\title{
Do Vehicle Recalls Reduce the Number of Accidents? The Case of the U.S. Car Market
}

\author{
Yong-Kyun Bae \\ SUNY-Stony Brook \\ Hugo Benítez-Silva \\ SUNY-Stony Brook
}

February 14, 2005

\begin{abstract}
The number of automobile recalls in the U.S. has sharply increased in the last decade and a half, and the number of units involved in these recalls are often counted in the millions. In 2004 alone, over 30 million vehicles were recalled in the United States. However, there is no quantitative evidence of the effect of recalls on safety. Without that evidence, the government and insurance companies have been reluctant to request and use more detailed recall information to increase correction rates. In this paper we empirically quantify the effect of vehicle recalls on safety using repeated cross-sections on accidents of individual drivers and aggregate vehicle recall data, to construct synthetic panel data on individual drivers of a particular vehicle model. We estimate the effect of recalls on the number of accidents, and find that recalls of a particular model reduce accidents of that model by $20 \%$. Recalls classified as "hazardous," and those initiated by foreign manufacturers are more effective in reducing accidents. We also find that vehicle models with recalls with higher correction rates have on average less accidents in the years following a recall, which indicates the importance of the role of drivers' behavior regarding recalls, on safety. The latter suggests that society as a whole, individual drivers, and insurance companies, could benefit from an initiative to take into account recall correction behavior when pricing auto insurance.
\end{abstract}

Keywords: Vehicle Recalls, Car accidents, Synthetic Panel Data, Auto Insurance. JEL classification: L62, C23

$\dagger$ We are grateful to John Hause, Chris Swann, Chris Snyder, Sam Peltzman, Ioana Marinescu, Adam Copeland, Katja Seim, Selcuk Eren, Na Yin, Huan Ni, Caroline Austin, and Anna Vellvé-Torras for their useful comments and suggestions. We also thank the participants of the Annual International Industrial Organization Conference held in Chicago. Benítez-Silva is also grateful to the Economics Department at the University of Maryland for its hospitality during the Fall of 2003, and to the Economics Department at UPF for its hospitality during the Summer and Fall of 2004. We bear sole responsibility for any remaining errors.

\# Economics Department, State University of New York at Stony Brook, Stony Brook, N.Y. 11794-4384, phone: (631) 632-7563, fax: (631) 632-7516, e-mail: ybaeeic. sunysb.edu 


\section{Introduction}

The main purpose of vehicle safety regulation is to reduce accidental harm. The National Highway Traffic Safety Administration (NHTSA) estimated the total economic cost of motor vehicle crashes in the year 2000 as being more than $\$ 230.6$ billion in terms of the present value of lifetime costs (NHTSA, 2002). Various regulations, such as seat belt regulation and speed limits, have been put in place to reduce these costs. ${ }^{1}$

In this paper we focus on vehicle recall regulation. The main purpose of this regulation is to remove unsafe and dangerous vehicles from the roads. The NHTSA sets a Federal Motor Vehicle Safety Standard to regulate vehicles so that manufacturers have to comply with the standard in order to sell their vehicles in the market. Even if they comply with the standard, if serious accidents occur or are expected because of potential defects, then a recall is required. According to the NHTSA, a recall should be issued when a vehicle or item of motor vehicle equipment does not comply with the standard or when there is a safetyrelated defect in the vehicle or equipment.

The recall system for motor vehicles in the U.S. was first introduced in 1966 to solve potential safety problems. Between 1966 and 2001, the NHTSA and manufacturers have issued more than 10,262 recalls, and the campaigns have been more active in recent years, especially since 1990 . The units per recall have also increased over time. More than 19 million vehicles were recalled in 2003, accounting for about $8 \%$ of U.S. registered vehicles, compared to 5\% in 1993 (Power and Lundegaard, 2004). According to the NHTSA, the total number of vehicles recalled increased by $61 \%$ during 2004 , to an all-time high of over 30 million vehicles.

Little is known, however, about the effect of vehicle recalls on the number of accidents, and there has been no quantitative analysis of this link. There are a number of reasons why there are relatively few studies of the effect of recalls on safety issues. First, recalls are specific to particular vehicle models. This means that each recall is issued for the stock of particular vehicle models that are in use on the road at a particular point in time. When the government or manufacturers find a defect that might cause serious accidents for the particular year-models, they have to decide whether or not a recall has to be issued and, if they do, how many units should be included. Recalls are often heterogeneous because each defective unit that might cause accidents has a different risk level. Therefore, the decision on whether to recall a vehicle, the scope, and the range of the defective parts are quite different according to the seriousness of the defects of the models. In addition to these problems, some recall data, such as recall costs, are

\footnotetext{
${ }^{1}$ See Viscusi, Vernon, and Harrington (2000, Ch. 22) for a detailed discussion of the many regulations, other than recalls, affecting the automobile industry.
} 
not available to researchers. And there is no direct link between recall data, accident data, and vehicle information. Because of these distinct characteristics of recalls and data limitation, economic studies related to safety issues have been scarce.

The arguments for and against the effect of vehicle recall on safety problems mainly have come from the manufacturers and the regulatory agents. The NHTSA states that its combined efforts (including recall campaigns, traditional safety regulations, education on safety driving, increase in road safety investment) result in a decrease of accidental harm, without providing supporting quantitative evidence. ${ }^{2}$

Some people who are in favor of solutions by automotive engineering, insist that one of the main determinants of the safety problem is the drivers' behavior. Evans (2002) divides the main determinants of safety into two categories: driver behavior and engineering, including recalls. ${ }^{3} \mathrm{He}$ argues that even though people pay a great deal of attention to the drivers' behavior, more focus still goes to crash-test ratings, product-liability trials and product recalls. He says that this is misplaced and overemphasized. He also insists that misplaced focus on vehicle factors has encouraged American drivers to regard safety as something out of their control, and the focus on safety equipment, such as airbags, misleads U.S. drivers into the belief that safety can be achieved without action on their part (see Peltzman 1975 for the seminal work on this argument). He suggests that policies that can change drivers' behavior or improve road environments are more desirable for safety because recalls do not save any lives. However, he acknowledges that quantitative evidence supporting this latter conclusion has not been developed. He said that he was not aware of any quantitative estimates. ${ }^{4}$ Our study provides a framework where it is possible to quantify the effects of recalls on safety.

Some discussions in the media, have suggested that not only there are too many recalls, but that people are paying relatively little attention to them. In a recent New York Times' article, Siwolop (2002), argues that people do not even know whether their products are the object of a recall and most consumers simply throw away their recalled products (e.g. dangerous toys, deteriorated meat) instead of returning products to the manufacturers. However, when the products are expensive durables and are more risky, consumers have stronger incentives to take corrective actions by returning their products, fixing them, or, as a default, changing their behavior. We provide the first quantitative evidence on the role of correction rates on safety.

Ours is the first empirical attempt, that we are aware of, to quantify the effect of recalls on vehicle

\footnotetext{
${ }^{2}$ L. Robert Shelton, the executive director of the NHTSA, gave testimony before the Transportation Subcommittee, United States House of Representatives on April 26, 2001.

3 Evans is the president of Science Serving Society, International Traffic Medicine Association (ITMA). He was affiliated with the Ford Company for 30 years and is the author of "Traffic Safety and the Driver".

${ }^{4}$ He said: "My best guess is zero. I believe that fixes due to vehicle recalls have saved zero, or close to zero lives. However, driving to have them attended to imposes the risk of death associated with additional travel—so, arguably, recalls increase traffic deaths, and certainly increase fuel use, etc. It seems to me that there ought to be much stronger evidence on the proposers of such policies to show evidence that some good flows from them." (email correspondence with the authors, April 11, 2003)
} 
safety. We use a methodology that groups individual drivers by types to produce synthetic panel data to analyze the effect of recalls on accidental harm, which is measured by the number of accidents. Meanwhile we control for the inherent unobserved heterogeneity of drivers, which is likely to matter a lot in explaining who gets into an accident, which could confound the results in a purely cross-sectional framework.

The results show that recalls reduce accidental harm, which is measured by the number of accidents. Specifically, recalls of a particular model reduce accidents of that model by around 20\%. Recalls classified as "hazardous," and those initiated by foreign manufacturers are more effective in reducing accidents. We also find that vehicle models with recalls with higher correction rates have, other things equal, less accidents in the three years after the recall, indicating the importance of the role of drivers' behavior, regarding recalls, on safety. The latter suggests that society as a whole, individual drivers, and insurance companies, could benefit from an initiative to take into account correction rates of outstanding and past recalls of the drivers' vehicles when pricing auto insurance.

Recent communications between the Insurance Institute for Highway Safety (IIHS) and the NHTSA, suggest that it is realistic to believe that this use of the recall information will materialize in the near future. Insurance companies, through the IIHS, have already started to pressure the government to release more information about recalls, such that it is possible to have the Vehicle Identification Numbers (VIN) of the vehicles recalled. This would allow a better monitoring of who fixes their cars, and open the door for insurance companies to take it into account in their pricing strategies. In a letter written in November of 2001, the Senior Vice President of the IIHS petitioned the NHTSA to require manufacturers to include the VIN numbers of the vehicles recalled in their recall announcements. This would reverse a decision of the NHTSA of 1986, which accepted a petition by manufacturers to drop this requirement, which had been in place since 1974. If this is granted, our results suggest that the likely increase in correction rates would have a welfare improving effect by reducing accidents. ${ }^{5}$

The remainder of the paper is structured as follows. Section 2 provides an overview of the recall system in the United States, and a short review of the related literature. Section 3 describes the data. Section 4 discusses the econometric models we estimate. Section 5 presents the empirical results, and Section 6 offers some concluding remarks, and discusses some policy implications of our results.

\footnotetext{
${ }^{5}$ The letter we refer to can be downloaded from the Internet at http://www.iihs.org/fed/nhtsa_ds_slo_110101.pdf
} 


\section{Background on the Recall System and the Related Literature}

\subsection{Definitions and the Recall Process}

The recall system for motor vehicles in the U.S. was first introduced in 1966 to solve potential safety problems. These problems are defined as defects that could cause loss of vehicle control such as steering, braking, fire, or repeated stalling. The National Traffic and Motor Vehicle Safety Act gives the NHTSA the authority to require manufacturers to recall vehicles with safety-related defects.

According to the NHTSA, a safety-related defect is defined as a safety-related problem that a motor vehicle (or item of motor vehicle equipment) poses. It may exist in a group of vehicles with the same design or manufacture, or items of equipment with the same type and manufacture. Nowadays, more vehicle models use the same parts jointly. Therefore, the effect of one defect on the safety of many vehicle models is more common than ever. The problems caused by any improper operation of the vehicles by drivers are not included in the recalls. Ordinary wear of equipment is also not included because it is the owners' responsibility to inspect, maintain, and replace parts on a regular basis.

Recalls may be either voluntary or mandatory. The government gives manufacturers the opportunity to announce recalls voluntarily. If the manufacturers do not agree with the government's recall decision, they can resolve the disputes in the courts.

Regarding the owners of the vehicles, the NHTSA releases information on how to complain when owners think that their vehicles have any safety-related problem. When they are injured in accidents, and think that their injuries are due to those problems, they are asked to file a defect report directly to the NHTSA. Alternatively, they may report the problems to the manufacturers. After recalls are issued, they have to take their vehicles to the places assigned by the manufacturers to be repaired.

The whole recall process is lengthy. ${ }^{6}$ For example, a Ford tire recall took more than 7 years from the first report until they reached a final decision. After a recall issuance, it also takes time to finish all corrective procedures because it depends upon the vehicle owners. The NHTSA requires manufacturers to report the correction rates after 18 months. On average, more than $40 \%$ of owners have not taken any corrective action by then.

There are many steps before a final decision to recall vehicles is made. Manufacturers may begin their initial recall process once they find some safety-related defects, even if there have been no complaint reports from their customers. This decision can be made based on their own investigative activities, given that they regularly monitor the quality of the vehicles. However, it is vital for either manufacturers or the

6 Information for this process can be obtained from the NHTSA. Details are described in its homepage, http : //www.nhtsa.dot.gov 
regulatory agents to receive the complaint reports from the owners in order to begin the recall process.

The first step of the process, which is taken by the regulatory agency, is known as "Screening." Once all the information from the reports is entered into a database, technical staff at the Office of Defects Investigation (ODI) of the NHTSA looks at the complaints and checks if there is any trend in accidents. If the trend shows an increasing risk of accidents, then the NHTSA starts an investigation.

The next step is called "Petition Analysis". However, this does not always follow "Screening" because any person can submit a petition to the NHTSA. For example, an owner who had a serious injury from an accident can write a petition to the NHTSA, when he (or she) believes that there may have been some defects in the vehicle which may have played a role in causing the accident. The role of the NHTSA is then to decide whether the petition is accepted or denied. Once it is accepted, more detailed investigation is conducted. In the final stage before recall issuance, the ODI sends a notice to manufacturers to give them an opportunity to argue against it or provide new evidence. Manufacturers can issue a recall at any of the stages, which makes the recall voluntary. If the manufacturers do not recall, then the NHTSA mandates recall issuance.

Once recalls are announced, the manufacturers send notice letters to their customers and also announce the recall through the media so that the vehicles can be brought in and the defects fixed. After that, the Recall Management Division, part of the NHTSA, monitors the post-recall process.

\subsection{Recall Trends}

Recall data were obtained from the National Center for Statistics and Analysis (NCSA), an office of the NHTSA. Recall data sets consist of detailed information on all individual recalls since 1966. Although we will impose some restrictions in the empirical analysis, we include all vehicle recalls in the discussion below to analyze the overall trends. The data include the following information on recalls of particular vehicles: model year, beginning and ending dates of manufacturing, potential number of units affected, potential number of units defective, recall initiator, the number of units corrected, hazard category, the summaries of defect, the possible consequences, and the correction required to eliminate the defect. The number of units affected might be different from the number of units defective. The latter is the number of units which actually have the problem, after investigating the defects carefully. The NHTSA assigns 4 different hazard ratings to each recall: A, B, C, and D from the highest to the lowest hazardous recalls. Here we define the "hazard recalls" as the ones that receive high hazard ratings: A or B.

Table 1 shows that manufacturers issued 3,886 recalls ( $74.3 \%$ of the total), while the ODI of the NHTSA initiated 1,032 recalls (19.73\%) and the Office of Vehicle Safety Compliance (OVSC) the rest. $54.96 \%$ of the recalls received the highest hazard rating, while $4.62 \%$ and $40.16 \%$ of the recalls were 
assigned the second and third hazard levels, respectively. Correction rates are defined as the ratio of the number of units repaired to the number of units recalled during the first 6 quarters after the recall. We have not been able obtain data on quarterly (or monthly) correction rates because the manufacturers do not disclose that information. The manufacturers report data on the number of units repaired during the first 6 quarters to the NHTSA. From the table, we see that the average correction rate is 55\%. This means that more than half of the units have been fixed within the first 18 months after the recall.

Figure 1 shows that the number of recalls has increased over time. In 1966, 57 recalls were issued. In 2000 , the number of recalls issued had increased to 663 . The number of recalls have substantially increased since the mid 1990s, and the increase in the number of hazard recalls is proportional to the number of all recalls. Since each recall involves a different number of units, we can plot the average number of units per recall over time. Figure 2 shows the annual average units per recall. Throughout the 1960's, on average 6,600 units per recall were issued. The units slightly increased to 8,940 in the 1970 's and to 18,956 in the 1980 's. However, the substantial change occurred in the 1990's where the average number of units rose to around 100,000 . We also see that the average number of units with high hazard ratings clearly increased. However, it could be argued that the increase in both recall issuance and units per recall may result from the increase in the market size. Column seven of Table 2 shows that the total number of vehicles sold has followed a different pattern. The level of 15.7 million vehicles sold in 1988 was not reached again until 1999 with 16.9 million, after a low of 12.6 million in 1991. In 200017.6 million were sold, and 16.6 million in 2001.

There are distinctly different patterns of recalls for domestic and foreign makers. Column three of Table 2 shows that the number of recalls from foreign vehicle manufacturers represents approximately one quarter of all recalls. This ratio is quite constant over time. We can also infer this pattern from Figure 3. From Figure 4 we can see that the ratio of the highest hazard recalls to all foreign recalls rose in the 1990s. This means that foreign makers have issued relatively more serious recalls even if the growth rates in recall numbers are similar. The fourth column of Table 2 shows who initiates the recalls. The proportion of recalls that are voluntary has fluctuated over time, but seems to be on the rise since the late 1990s, accounting for over $3 / 4$ of the recalls.

Table 3 shows more details about recalls in the 1988-2001 period. The total number of recalls from 1988 to 2001 was 5,233. The average value of the potential number of units affected was 94,237. The numbers of units that are issued to each recall range from one to 32 million. The NHTSA assigns 4 different hazard ratings according to the degree of possible risk. The value is 4 (which corresponds to category A) if a recall receives the most hazardous rating. The lowest hazardous rating here is 1 (which corresponds to category D). The average value was 3.143 . 
One last issue to be mentioned about the recalls is that although a recall is usually issued on a particular year-model, some recalls have been issued for two or more year-models. We solve this by grouping data on sales and correction rates for all year-models. Second, a recall can be issued to different vehicle models if they are produced from the same production line and the defective parts are loaded into different models. Then the number of units should be divided by its share. For example, if 1,000 vehicles are issued recalls, and among them 500 units are issued to the Ford Mustang while the rest are to the Ford Taurus, and we are focusing on the recall for the Mustang, then the units should include only 500. Table A1 in the Appendix shows an example of multiple year-models and of multiple models.

\subsection{Previous Literature}

Many researchers (e.g., Ashenfelter and Greenstone, 2002) have studied the effects of direct safety regulations, such as mandated speed limits, rather than recalls. On the other hand, the economic literature on automobile recalls have not provided any quantitative evidence on the effects of these recalls on safety. Most studies related to recalls have focused on issues other than safety.

Crafton, Hoffer, and Reilly (1981) focus on the effects of recalls on consumers' demand for the vehicles, and Nichols and Foumier (1999) study the effects on manufacturers' reputation. Jarrell and Peltzman (1985) analyze the stock market's response to the news of product defects. Using medical and automobile recall data, they show that the capital market internalizes the indirect costs of recalls and these costs are large enough to dominate direct recall costs. ${ }^{7}$ These costs can be a considerable deterrence to producing risky products, and give the manufacturers incentives to make safer vehicles. Rupp (2004) using more recent data, and focusing on the attributes of the recalls, finds similar results. Hartman (1987) assesses whether the resale market for cars discounts the information on recalls, and finds fairly substantial effects in terms of lower prices for cars that have been subject to important recalls.

Hoffer, Pruitt, and Reilly (1994) show that recalls of domestic new model vehicles with severe safety defects, generate the largest corrective rates. They define the rates as the ratio of the number of the units repaired to the number of the units issued for the vehicle model. They argue that it is much easier for the owners of domestic vehicles to access the designated repair shops than the owners of foreign vehicles because the domestic manufacturers have much more well-organized dealerships across the country. Therefore, the time cost is lower for the owners of domestic vehicles. Accordingly, domestic vehicles' correction rates are higher. These authors did not study whether these corrective rates directly affected accidents.

\footnotetext{
${ }^{7}$ Direct costs are the ones that are used to correct the defects: repair costs, advertising costs, etc. Indirect costs are the ones that are incurred through the financial and the goods markets due to recalls, if these exist.
} 
Rupp and Taylor (2002) investigate the initiation of recalls. They find evidence that the government initiates less hazardous recalls which affect larger number of units, while the manufacturers issue inexpensive recalls. They also analyze the determinants of recall corrective actions. Again, their study does not deal directly with the safety issue.

Huble and Arndt (1996) use car crash data to analyze how this information can be used to support the different positions in a safety dispute. They use a particular vehicle model (a GM truck) to see the effects of changing the fuel tank location on safety by comparing it with other similar types of trucks. They find that the conclusions might be quite different even if the manufacturer and the government use the same data source. This paper does not directly deal with recalls, but compares the damage to the vehicles and the loss of life before and after a model design change. However, they do not examine the net benefit of recalls resulting from a possible reduction in the number of accidents.

\section{The Data}

We use accident data from the General Estimation System (GES), and recall data available from the NHTSA. We also obtained vehicles' sales data and information about new models from Ward's automotive yearbook. The accident data that are used in estimation come from the NCSA. The GES contains a nationally representative sample of all vehicle accidents that have happened based on police reports.

The system designates 60 areas that represent geographic and demographic regions. Every week data collectors visit around 400 police stations within these areas. They randomly select about 50,000 Police Accident Reports (PAR) each year. The system started its operation in 1988, and data files through 2001 were, until recently, freely available online. These data files consist of 3 distinct data sets: the accident file, the vehicle/driver file, and the personal file. The accident file contains information describing environmental conditions and roadway characteristics at the time of the crash, as well as information about the severity of the injuries for the passengers involved. The vehicle/driver file contains information describing the vehicles involved in the accidents and their drivers. It includes information such as make and model of the car and model year of the car. The personal file contains general information describing all persons involved in the crash; drivers, passengers, and pedestrians. It includes information such as age, sex, and injury severity. We merge all these data sets to have the information in a format amenable to econometric modeling.

The second source of information is obtained from Ward's annual automotive yearbook. These data contain all U.S. new vehicle sales by line. These sales data will be combined with recall data to produce the recall variables. The third source of information contains data on recalls. In order to match with the 
first two data sets, we use recall data starting in 1988. For the empirical study, we will use data on the potential number of units affected, the dummy variables on the manufacturers, calendar year of recall, and hazard category code for each recall.

The variables used in the empirical analysis are defined in Tables A2 and A3, in the Appendix, and explained below.

\subsection{Measuring Accidents by Driver Type}

Most literature related to safety issues uses either fatality rates or accident rates as measures of accidental harm. However, this does not fit well with our objectives. The variable we choose should reflect common characteristics that are specific to the type. Furthermore, data should be identified by the vehicle models because recalls do not have a geographic dimension.

We define the types by age, gender, whether the driver was on the striking vehicle, and by the vehicle model. The latter has the effect of reducing the number of individuals by group but it captures many unobservable characteristics about the drivers, if we believe that the car that someone drives is an indicator of income, wealth, and in some cases attitudes towards risk. A good measure of accidental harm for a particular driver type is the number of accidents of that type. Since each type contains the same kind of drivers and these drivers drive the same vehicle models, the numbers of accidents are different across types and over time. These differences between the members of a type reflect the frequency of the accidents and they are unique to each type. Therefore, these numbers measure relative accidental harm. ${ }^{8} \mathrm{We}$ construct annual data on the number of accidents in which a particular type has been involved. From the GES data set, we aggregate data, which report individual accidents by model, to produce the yearly number of accidents of a particular vehicle model.

We define the dependent variable $\ln A_{\text {Acc_Type }}$ it as the natural logarithm of the number of accidents in which a particular driver type was involved in a given year. With this definition of the dependent variable, we face one potentially serious problem. The number of vehicles in use is not constant over time because the vehicles that had severe accidents will be removed from the road. We do not observe the number of vehicles that have been dropped from the road over time. Therefore, if we simply use the number of vehicles in use on the road regardless of the vehicle year-model, we have to know the number of vehicles that have been discarded during a particular year. One solution is to restrict the number of vehicle-year models. It is reasonable to restrict the vehicles up to the 5 year-old ones because the number of vehicles in

\footnotetext{
${ }^{8}$ In fact, each accident has different accidental harm measured by severity. Therefore, it does not strictly reflect the true value of the harm for the type. But if we use a weighted value using information on severity for the composite type, then the estimation is likely to be an error-ridden one. Bae (2004) develops a "severity model", using only cross-sectional data. The results of that research show that recalls reduce the severity of injury of drivers.
} 
use does not change much during the first 5 years. Ross and Wenzel (2001) argue that $97 \%$ of 5 year-old vehicles are still in use on the road. Therefore, it is reasonable to restrict the data up to 5 year-old or newer vehicle models.

Another reason for this restriction is that one of the main determinants of accidents may come from drivers' negligence in maintenance as the vehicles are getting older. For example, if a vehicle is a 20 year-old model, then the probability that the original defects of the vehicle cause an accident is very low. Also, around $90 \%$ of the recalls are issued within 3 years after the introduction of the new-year model. Therefore, our conclusions are unlikely to be affected by restricting our attention to newer vehicle data.

When estimating the effect of correction rates on the number of accidents after a recall, the dependent variable is calculated as the natural logarithm of the average number of accidents of a particular vehicle year model in the three years after the particular recall. ${ }^{9}$ In this case the level of observation is the recall of a particular vehicle year model. When a recall includes more than one year model, or more than one model of the same manufacturer, we aggregate across years and models.

\subsection{Explanatory Variables}

The main independent variables of interest are the ones related to recalls. Each recall has a different number of units, with some recalls containing a small number of vehicles while others include a substantially larger number. To account for this we construct a weighted recall variable. This is achieved by calculating the ratio of the number of vehicles affected by a particular recall to the number of the vehicles in use on the road. To avoid possible endogeneity problems, the denominator will be the sum of the vehicles sold in the four years prior to the year of that particular recall. We define

$$
\text { Rec_Rate } e_{i t}^{v}=\frac{\sum_{n=1}^{N}\left[R_{i n t}^{v}\right]}{\sum_{j=t-1}^{t-4}\left[S_{i j t}^{v}\right]},
$$

where $R_{i n t}^{v}$ is the number of the units of a recall $n$, issued at time $t$, for the vehicle model $v$. The vehicle model includes only year models no older than 5 years (from $t$ to $t-4$ ). $S_{i j t}^{v}$ is the number of units of the $j$ year-vehicle model that are on the road as of time $t-1$. All drivers in group $i$ drive the same vehicle model $v$. This variable represents how many vehicles are at risk among all vehicles on the road as of the year before the recall, and also how many vehicles are to be fixed due to recall issuance. In the econometric specification, the coefficient on this variable can be directly interpreted as the effect of recalls on the number of accidents in percentage terms, given the nature of the dependent variable. The effect should be understood to affect only the units recalled.

\footnotetext{
${ }^{9}$ If the recall happened in the first six months of a particular year the three years used include the year in which the recalled was issued. Otherwise, include the three years following the recall.
} 
Notice that issuance itself is different from correction. However, it sends a signal to the drivers whose vehicles are potentially dangerous. The signal may change the drivers' behavior: drive less frequently, or drive more carefully until their vehicles are fixed. Therefore, recall announcements themselves may affect the number of accidents by either changing drivers' behavior or fixing the defects. In the empirical work, we will use data on correction rates to make the argument that although we do not know the effect that changes in behavior have on accidents, we can show that correction rates do matter.

When we use the whole sample of accidents the indicator Strike takes the value 1 if the vehicle struck other vehicles or objects. In the specifications that include all accidents, the variable Strike is used to distinguish the role of the drivers' faults and (or) the vehicle defects. Age is also an important control. We divide individuals by their age into 4 groups. The first age group is for drivers under 26 . The second age group is between 26 and 35, the third age group consists of those aged 36 to 49, and the fourth for those 50 and older.

Another important explanatory variable reflects whether the manufacturers have launched a new vehicle model in the period of analysis. This is important because one natural reaction by manufacturers to a large number of accidents tied to defects is to fix the problems in a new model. However, new models can also introduce an array of new problems, especially if car makers feel the pressure to launch new models to keep up with market rivals. We build upon the definition used in Berry, Levinshon, and Pakes (1995), and consider that a new model was introduced if either horsepower changed by $10 \%$ or more, or one of the other indicators (width, length, and wheelbase) had a substantial change, considering the usual changes in that type of indicator.

Another explanatory variable is a measure of the vintage of the cars on the road of a particular model. We calculate this variable as the percentage of cars of a particular model that belong to the two latest year models. Another logical control is the total number of cars on the road of a particular vehicle model. We use the sum of all the cars of a particular model sold in the 4 years preceding the year of observation. This helps control for the level effect correlated with the probability of being in an accident.

In all specifications we add year dummies to capture the changes in accidents as the number of total vehicles on the road evolves in the 1988 to 2001 period. We also include binary indicators for the different vehicle models. These variables are also used to group drivers into the different types. Therefore, these indicators are constant over time, but changing across the types. Table A4, in the Appendix, provides the list of vehicle models included in the analysis.

When estimating the effect of correction rates on the number of accidents after a recall, the key independent variable is the correction rate of the particular recall analyzed. This measures the proportion of vehicles that have been fixed, out of the original pool of defective vehicles. These rates are reported by 
the manufacturers. Other independent variables in that analysis include the average sales of that particular year model, the size of the recalls and its square, the number of recalls after the particular recall of analysis, whether the recall was considered hazardous, and the manufacturer of the vehicle recalled.

\subsection{Summary Statistics}

There are roughly 250 vehicle models in the U.S. automobile market and the number of the models varies slightly over time. In our analysis we choose the vehicle models according to the following selection criteria: First, while $97 \%$ of light vehicles are still on the road, only $93 \%$ of trucks are on the road within 5 years. Therefore, we concentrate on light vehicles and some SUVs. ${ }^{10}$ Second, we add more new vehicles that appear recently in the market if their market shares are substantially increasing over time. Third, we exclude models with a market share under one percent of the market of current year models. Fourth, during the time period of interest, some firms have merged and other firms stopped production of a particular model. We have excluded those models at this time. Overall, we include 20 models whose units of the vehicle model sales are consistent over time. These vehicle models have been popular and have large market shares over time.

In Table 4 we provide summary statistics for the full sample (72,239 observations) of individual level accidents of our 14 years of repeated cross-sections. Almost $52 \%$ of individuals involved in accidents are males, around $43 \%$ are aged over 35, and the most popular vehicle models in our sample, are Escort, Accord, Cavalier, Taurus, and Civic. This is very much in line with the market shares in the U.S. car market in this time period.

Table 5 shows summary statistics once we have grouped individuals by composite types. There are more than 4,100 observations in this data set, which comes from following the 320 types (which include 20 different vehicle models, four age categories, two genders, and whether the vehicle was the striking one) for 14 years. The average composite type got into 18 accidents on average during a year. The maximum number of accidents among all groups is 141 . Regarding the recall variables, we see that $14 \%$ of the vehicles on the road have been recalled. The maximum value is larger than one because one recall may include more than one defective part, and that appears here as recalling a larger number of vehicles. 55\% of the vehicles for which recalls were issued, received hazard ratings (A or B). This implies that almost half of the units of all recalls are non-hazard recalls. We will see that recalls from this $55 \%$ have a large effect on safety. In our empirical work, and in order to compare our empirical strategy to the seminal work

\footnotetext{
${ }^{10}$ Another justification for this is that trucks are mostly commercial. The depreciation rates of trucks are higher. However, we decided to include SUVs in the sample because recently we have seen more frequent and notorious recalls for SUVs, even though SUVs are in the truck category, most of SUVs are not used for commercial purposes.
} 
on synthetic panels, we also divide our sample only by the 20 vehicle models we analyze in this paper. We will see later that the results do not change much, but allow us to see the trade-offs between minimizing the possible measurement error problem involved in analysis of repeated cross-sections, and computing efficient parameter estimates of the variables of interest, the efficiency of which is in this case a function of the homogeneity of the composite-types.

Table 6, provides summary statistics for the variables used in the correction rate estimation. The average number of accidents for the recalls analyzed is over 200, and the correction rate for the recalls in the sample is $68.9 \%$, the average units sold in the three years after the recall are 673,000 , the average size of the recalls included in the sample is 218,000 , and the number of recalls after the current recall, of the same year model in the three years after the original recall, is 2.1 .

\section{The Econometric Model}

\subsection{Number of Accidents and Recalls}

In order to analyze the effects of recalls on safety, it would be ideal to have panel data to control for the individual specific heterogeneity that results in potentially different outcomes when faced with a given situation on the road. We obviously also need to control for vehicle characteristics, manufacturers decisions regarding new model introduction, and characteristics of the drivers. The problem is that there are no panel data on accidents of individual drivers, so it is essentially impossible to observe an individual driver's behavior and his or her response to recalls over time. Only repeated cross-sectional data on accidents is available, which does not allow us to control for individual specific driving abilities. Without those controls our models can say relatively little about the effects of recalls on safety over time.

To circumvent this problem we propose to produce synthetic panel data using the repeated crosssections independently collected each year, following the work of Deaton (1985) and Verbeek and Nijman (1992). ${ }^{11}$ For this, we use the concept of a 'type' or 'group'. This notion starts with the fact that, corresponding to individual drivers' behavior, there will be a group version of such behavior, if we group drivers by some characteristics, and the type of car they drive. If we group drivers whose characteristics are similar into a type, we can then track the drivers' behavior over time through these types. Within a group, we have drivers whose driving characteristics are similar, and we can consider this type as if it were an individual. Browning, Deaton, and Irish (1985) provide an empirical application using British data

\footnotetext{
11 Moffitt (1993), Collado (1997), Girma (2000), McKenzie (2004), and Verbeek and Vella (2004) focus on the estimation and identification of dynamic models using a time series of repeated cross-sections. The demands on the data by those types of models are considerably higher than in the linear pseudo-panel data model that we estimate.
} 
from the 1970's, where they divide groups by aggregating over age-cohorts, and by whether the head of the household was a manual worker. Attanasio and Weber (1993), and Blundell, Browning, and Meghir (1994) use a very similar specification, also using British expenditure data, and divide the groups by age.

One of the major differences among these drivers is that they drive different vehicle models. Since we investigate the effect of recalls of particular vehicle models on accidents, the type must also contain information on vehicle characteristics. If we again divide these drivers by vehicle models, then we can control for observed drivers' and vehicles' fixed effects. We also believe that dividing by vehicle models also controls for additional unobserved characteristics of drivers correlated with the type of car they drive, such as income, wealth, or even attitude towards risk. Since a type contains a particular vehicle model and a driver's type at the same time, we call this "a composite type".

This netting-out effect enables us to statistically distinguish characteristics that are related to the defects from all others. Therefore, our level of observation is a group of individual drivers who have the same personal characteristics and drive the same vehicle model at the time of the accident. Now each composite type appears repeatedly over time. If we have enough composite types, successive cross-sections of accident data will generate successive random samples from the composite type population.

\subsubsection{The Measurement Error Problem}

Each composite type has its own characteristics, like an individual driver. We need to use summary measures that represent characteristics of each type, not individual measures because they should show common characteristics of individuals within a type. Composite type means are the statistics we choose in this setting. However, if we use sample means of the type, then we face a measurement error problem. The unobserved effects are no longer constant over time since composite type population means are different from composite type sample means. These errors are added to the unobserved type effects so that the effects change over time. Deaton (1985) showed that one can use the synthetic panel data model solely from cross-sectional data if large numbers of observations are available in each period, or if the estimators are corrected for the error in variables problem.

Verbeek and Nijman (1992) arrived at the same conclusion, and they investigate the conditions that make this approach valid. Their conclusion is that the larger the number of observations per type, the less severe the measurement error problem will be. The latter set of authors, and Collado (1997) pointed out that there is a trade-off between the number of observations per type and the number of types, given a sample size. Collado's argues that the cross-sectional sizes of the most widely used data sets are relatively small, therefore the problem comes from the fact that we are trying to make as many types as we can, but with relatively small number of total observations, and the measurement error becomes serious. In general 
in order to make the measurement error less serious the number of observations per cohort should be large enough, but not so large that the variance of the parameters of interest is too large.

Measurement error, however, is unlikely to be an issue in our preferred specifications with finer types, because we are not averaging any characteristics within the groups. The dependent variable is not an average but a cell count (the number of accidents in the cell) and the independent variables are in all cases either the variables we use to divide the types, or in the case of the recall rate the variable is the same number for all the vehicles of a particular model in a given year.

\subsubsection{Econometric Specification of the Number of Accidents Estimation}

Consider the following equation to represent the relationship between accidental harm of a particular individual and the possible causes involved in the accident,

$$
y_{d t}=f_{d}\left(\mathbf{x}_{d t}, \xi_{d t}^{v}, \zeta_{d t}^{v}, c_{d}, \tau_{d}^{v}\right)
$$

where $y_{d t}$ measures accidental harm that a driver $d$ had at time $t . d=1, \ldots, D . D$ is the total number of drivers who had the accidents at time $t . \mathbf{x}_{d t}$ are the driver $d$ 's characteristics that affect the accidents in which he is involved. They include the observed factors that are used to group drivers. $\xi_{d t}^{v}$ is the vehicle characteristics that are not related to the defects, where $v$ is an indicator of the vehicle he or she drives. $\zeta_{d t}^{v}$ are the vehicle characteristics that are related to the defects. $c_{d}$ is the driver's unobserved factors. $\tau_{d}^{v}$ is the vehicle's unobserved factors.

A convenient functional form to express the relationship is

$$
y_{d t}=\mathbf{x}_{d t} \gamma_{1}+\xi_{d t}^{v} \gamma_{2}+\zeta_{d t}^{v} \gamma_{3}+c_{d}+\tau_{d}^{v}+\varepsilon_{d t} \quad t=1, \ldots, T \quad d=1, \ldots, D
$$

where $\varepsilon_{d t}$ is the unobserved random disturbance. The aggregating process changes the latter equation to

$$
\tilde{y}_{c t}=\tilde{\mathbf{x}}_{c t} \beta_{1}+\tilde{\xi}_{c t} \beta_{2}+\tilde{\zeta}_{c t} \beta_{3}+\tilde{c}_{c}+\tilde{\varepsilon}_{c t} \quad t=1, \ldots, T \quad c=1, \ldots, C
$$

where $c$ denotes a 'composite type'. $\tilde{y}_{c t}=\left(1 / c_{n}\right) \sum_{d=c_{1}}^{c_{n}} y_{d t} . \tilde{\mathbf{x}}_{c t}=\left(1 / c_{n}\right) \sum_{d=c_{1}}^{c_{n}} \tilde{\mathbf{x}}_{d t} . \tilde{\xi}_{c t}=\left(1 / c_{n}\right) \sum_{d=c_{1}}^{c_{n}} \tilde{\xi}_{d t}$. $\tilde{\zeta}_{c t}=\left(1 / c_{n}\right) \sum_{d=c_{1}}^{c_{n}} \tilde{\zeta}_{d t} . \quad \tilde{c}_{c}=\left(1 / c_{n}\right) \sum_{d=c_{1}}^{c_{n}} \tilde{c}_{d} . n$ is the number of observations in the composite type $c$. The variables become the types' mean values, and represent group characteristics that affect the dependent variable. Since the variables in $\xi$ are the dummy variables indicating vehicle models, the unobserved vehicle fixed effect is absorbed into these variables. Rewriting the last equation

$$
\tilde{y}_{c t}=\tilde{\mathbf{x}}_{c t} \beta_{1}+\sum_{v=1}^{V-1} d_{v} \beta_{2 v}+\tilde{\zeta}_{c t} \beta_{3}+\tilde{c}_{c}+\tilde{\varepsilon}_{c t} \quad t=1, \ldots, T \quad c=1, \ldots, C
$$

where $d_{v}$ is the vector of vehicle dummies. 
This grouping controls for driver and vehicle characteristics that are not related to the defects. Then the difference in accidental harm over time and across types may come from other observable factors including the changes in recall variables and other sources of unobserved heterogeneity between the types. By making the composite type, some unobserved components are controlled by the panel data strategy. However, the error term, $\tilde{\varepsilon}_{c t}$, now contains "a type-specific trend" in the process of aggregation. If there exists a cohort-specific trend, then an additional source of heterogeneity arises. Therefore we need a separate term to account for this. We can then write

$$
\tilde{y}_{c t}=\tilde{\mathbf{x}}_{c t} \beta_{1}+\sum_{v=1}^{V-1} d_{v} \beta_{2 v}+\tilde{\zeta}_{c t} \beta_{3}+\tilde{c}_{c}+T g+\varepsilon_{c t} \quad t=1, \ldots, T \quad c=1, \ldots, C
$$

where $\tilde{\varepsilon}_{c t}=T g+\varepsilon_{c t}$. In the panel setting, $t=1988, \ldots, 2001$ and $c=1, \ldots ., 320$, where $t$ is a year and $c$ is a composite type. To express the equation in a simple matrix notation, we redefine the equation as

$$
y_{i t}=\mathbf{X}_{i t} \beta+c_{i}+\varepsilon_{i t} \quad t=1, \ldots, T \quad i=1, \ldots, N
$$

where $y_{i t}=\tilde{y}_{c t}, \mathbf{X}_{i t}=\left(\tilde{\mathbf{x}}_{c t} \vdots \sum_{v=1}^{V} d_{v}: \tilde{\zeta}_{c t}\right), \beta=\left[\beta_{1} \vdots \beta_{2} \vdots \beta_{3}\right]^{\prime}, c_{i}=\tilde{c}_{c}$, and $\varepsilon_{i t}=\tilde{\varepsilon}_{c t}$. Now $i$ represents a composite type. $\mathbf{X}_{i t}$ contains observable variables that change across $t$ but not $i$, variables that change across $i$ but not $t$, and variables that change across $i$ and $t$. We call $c_{i}$ the unobserved composite type effect.

We can modify this model to account for a type-specific trend,

$$
y_{i t}=\mathbf{X}_{i t} \beta+\mathbf{z}_{i t} \mathbf{a}_{i}+c_{i}+\varepsilon_{i t} \quad t=1, \ldots, T \quad i=1, \ldots, N
$$

where $\mathbf{z}_{i t}=(1, T), \mathbf{z}_{i t}$ is $1 \times 2, \mathbf{a}_{i}$ is $2 \times 1, y_{i t}$ is $1 \times K, \mathbf{X}_{i t}$ is $1 \times K, \beta$ is $K \times 1$. The latter is the equation we use for estimation of the traditional synthetic panel data model. For the model, the strict exogeneity assumption of the error terms with respect to the regressors is imposed. After constructing this basic panel data structure, the same inference procedure as in traditional panel data models can be used. ${ }^{12}$

Finally, once we construct our composite types in a finer fashion, the measurement error issues disappear, and we are left with a traditional panel data estimation of equation (8), where the level of observation is the composite type, and where the maintained assumption is that the unobserved heterogeneity components, which we are accounting for, are group specific, and that it is meaningful to track the number of accidents of these types over time.

\footnotetext{
12 We could use count data techniques to estimate our models. However, given that there are almost no zeros in our data set, the easier interpretation of the coefficients using standard moment condition methods, the appropriateness for inference of regression methods, and the fact that none of our main results change in any significant way, we have decided to report the results using standard panel data regression techniques.
} 


\subsection{Correction Rates Model}

When estimating the effect of correction rates on the number of accidents after a recall, we estimate the following equation

$$
y_{i}=\mathbf{X}_{i} \beta+v_{i t} \quad t=1, \ldots, T \quad i=1, \ldots, N
$$

where $E\left(v_{i t} \mid \mathbf{x}\right)=0$. Here $y_{i}$ is the natural logarithm of the average number of accidents of the year model recalled, in the three years after the recall, and the explanatory variables $X_{i}$ are the ones explained in the data section, including our main variable of interest in this estimation, that is, the correction rate of the recall for that particular year model, as reported by the manufacturer 18 months after the initial recall. If more than one recall was issued in a given year we take the one with the highest hazard rate, or the one that recalls the largest number of units, if the hazard levels are the same.

\section{Empirical Results}

\subsection{Do recalls reduce the number of accidents?}

Table 7 reports the estimates by Random Effects of two different specifications of the panel data models applied to repeated cross-sections of accidents and using vehicle models recall data. In this table we focus only on the 20 vehicle models we analyze, and we report the effect on the number of accidents of all recalls and also hazardous recalls. The first two columns group accidents only by the type of vehicle model involved in the accident, and do not include covariates that need averaging within groups. This specification essentially uses a panel of the vehicle models we have chosen to analyze, and studies the connection between the accidents affecting those vehicles and the recalls issued on those vehicles. Columns three and four use standard synthetic panel specifications (Deaton 1985), and while grouping accidents only by vehicle model, they do include covariates that are the result of averaging characteristics of the drivers within each group. These latter parameter estimates are potentially subject to measurement error. However, the large number of observations in each of those groups, ameliorates this problem considerably. As shown

in Table 8, the number of observations in most of the groups is in the several hundreds. Here each group represents a vehicle model.

The results from both specifications are quite similar, and already show the significant negative effect of the recall rate on the number of accidents. The parameter estimate varies between $19 \%$ to $27 \%$ depending on whether we use all recalls or only those classified as hazardous. This coarse grouping by vehicle model, however, results in the inefficiencies discussed in the literature, due to the prevalent heterogeneity within each group. 
In Tables 9 to 12 we improve upon the specifications of Table 7, in that the groups are now defined much more finely. A type is now defined not only by vehicle model, but also by gender, age group, and by whether the vehicle was the striking one in the accident. Overall we have more than 300 groups. This fine grouping allows us to estimate the parameters of interest in a considerably more efficient way, and also allows us to avoid completely the measurement error problem, since the problematic covariates of interest are in this case just indicators of whether the accident belongs to a particular age group, gender group, or striking group, and are not averaged within groups. At the same time, thanks to the homogeneity of the groups we reduce the efficiency problem apparent in the estimates of Table 7.

Table 9 reports the estimates by random effects of the panel data model in equation (8), for the whole sample of types, including accidents by vehicles that were struck. The main finding is that recalls are effective in reducing accidental harm measured by the logarithm of the number of accidents in all specifications. The coefficient of our main explanatory variable of interest, Rec Rate, is negative and statistically significant at the $1 \%$ level or better. The first column of the table includes all vehicles, both foreign and domestic. Recalls are predicted to reduce the number of accidents of the vehicles recalled by $17.6 \%$. The effect is stronger for foreign vehicles, $21.1 \%$, while it is $16.5 \%$ for domestic vehicles.

The rest of the coefficients in the table are almost always highly significant. Males are predicted to have more accidents, but only for domestic vehicles, the Strike indicator is positive and significant, likely capturing the fact that in a number of accidents only one car (the striking car) was involved. The age dummies have the expected signs, but only when we take all recalls into account or only foreign ones. For domestic recalls the parameters are not very precisely estimated.

The variable that indicates whether a new model was introduced in a given period, New Model, has a positive and significant effect, indicating that although new models are likely to fix problems with previous editions of the car, new features and engineering changes lead to a higher number of accidents, other things equal. The many pressures that car makers have to launch new products every year seem to be resulting in larger and larger number of problems with the vehicles. This effect seems to be offsetting the possible improvement in engineering that comes with the introduction of a new model.

The differences between domestic vehicles and foreign vehicles becomes especially clear through the coefficients estimated for our Vintage indicator. This variable indicates the percentage of cars, out of the total cars sold in the last 5 years, which belongs to the latest 2 year models. The overall effect of this rate is, rather unexpectedly, positive, but this is entirely due to the domestic vehicles, since the coefficient is actually negative for foreign vehicles. This means that having relatively newer cars on the road increases the number of accidents for domestic vehicles, while it reduces it for foreign vehicles, indicating a likely difference in quality, given that we are controlling for unobserved and observed characteristics of drivers. 
This is in line with the widely spread belief that foreign manufacturers (represented here by the Japanese auto makers) have a more reliable and better product that American manufacturers.

Not surprisingly, the number of vehicles on the road of a particular model has a strong positive effect on the number of accidents, with the model predicting that an increase in 100,000 cars on the road increases the number of accidents by around 14\%. For domestic vehicles this goes up to around $19.2 \%$.

We also include in the estimation binary indicators of the different vehicle models driven by our composite types. Since the Dodge Caravan was omitted from the specification, the coefficient for any particular model is the relative difference in accident rates for that model and the Caravan. We have also experimented with omitting other vehicle models, such as the Ford Mustang, the results were essentially unchanged. Regarding these indicators, notice that even after controlling for the size of the market, more popular vehicle models like Escort, Accord, Mustang, or Civic, are predicted to be positive related to the number of accidents on the road.

Notice that the overall fit of the model is quite good, explaining almost $60 \%$ of the variation in the number of accidents, and doing a especially good job in explaining the variation between the different types of drivers. The fit is especially good when restricting attention to the sample of foreign recalls.

We have performed the Breusch-Pagan Lagrange multiplier test for the presence of an unobserved effect, and we can soundly reject the OLS model in favor of the Random Effects structure. Also the Hausman test cannot reject the random effects assumption versus the fixed effects characterization of the model. This is not surprising since the very nature of our data, a cross-section of accidents randomly drawn from the population of accidents on the road each year, fits perfectly with the assumptions of the Random Effects model. Also, it is difficult to argue that the unobserved heterogeneity component that affects our composite-type of driver has much to do with the covariates related to the vehicle model they are driving. Therefore, in all the tables that follow we report the results of a modified random effects model that contains a time-trend.

Table 10 concentrates only on hazardous recalls, given that it could be argued that fairly minor recalls are unlikely to have any effect on the accidents on the road. The results do not change much from the ones reported above, except that the recall effects are now larger across the board. For the full sample they go up to $25 \%$, for domestic vehicles is around $19.3 \%$, and considerably larger for foreign vehicles, reaching almost $40 \%$. This seems to indicate that when foreign manufacturers (or the government) recall foreign cars these recalls are more effective in reducing accidental harm, conditional on the same level of hazard of the recalls. The rest of the coefficients of interest do not change in any significant way.

Tables 11 and 12 concentrate only on accidents by the striking vehicles, dropping the information on the cars that were struck. It could be argued that including in the analysis vehicles that were struck could 
be rather noisy, given that the police seemed to have identified them as playing a fairly passive role in the accident. The latter, however, is unclear. A vehicle could be the struck one but be the one that provoked the accident. The classification by the police can potentially be a noisy measure of the actual events of the accident. Therefore, the results of these tables should be taken as a sensitivity analysis of the results of the previous tables. In these tables we do not report, for the sake of brevity, the indicators for vehicle models, since they do not change in any significant way from those reported in Tables 9 and 10.

Table 11 reports the result for all types of recalls, and the estimates again are fairly similar to those of the overall sample of vehicles. Recalls reduce the number of accidents by between $10.9 \%$ for domestic vehicles, to about $20.9 \%$ for foreign vehicles. Males are more likely to get into accidents (except for foreign vehicles in which case the coefficient is highly insignificant), introducing a new model is correlated with a higher number of accidents, and the size of the market for a given model increases the accidents on the road. Notice again the effect of the vintage of the cars on the road, the newer the domestic vehicles on the road, the more accidents. But this reverses for foreign vehicles. The specification in Table 11 has an even better fit than the previous tables, with an $R^{2}$ above $60 \%$, and with a clear support of the random effects model compared with the OLS one.

Finally, if we turn to Table 12, we concentrate on the hazard recalls, among the striking vehicles. The results change relatively little from the ones in the previous tables. The main change is that for domestic vehicles the recall effect is not very precisely estimated, but for the whole group of vehicles the effect remains at around $21 \%$, and for foreign vehicles is still around $36 \%$.

\subsection{Are higher correction rates of recalls linked to less accidents?}

The main results of the paper presented in the previous subsection leave one question open. Are recalls effective because people fix their cars or because they change their behavior after they know about the problem, even if they do not take the car to be fixed? The debate on how behavior adjustments by individuals can affect safety outcomes goes back to Peltzman (1975), and a large number of articles with mixed empirical results, including Crandall and Graham (1984), and more recently, using Canadian data, Sen (2001). It is unlikely that the reduction in accident rates caused by recalls is all due to behavioral adjustment, given that information is sent to drivers from manufacturers only about the need to fix their cars, not about how dangerous the defect could be. It is clear, however, from the numbers on correction rates that not everyone takes their cars to the shop to be fixed. Manufacturers report an average correction rate of about $68.85 \%$ for the recalls of the vehicle models analyzed in this paper. The number would not be very different if we were to take all recalls issued in the last few years.

The estimation of equation (9) presented in Table 13, provides evidence of the importance of correction 
rates in the number of accidents after a recall. We use the sample of recalls linked to the 20 vehicle models used in the previous section (therefore we exclude recalls of year models older than 5 years), and after restricting attention only to one recall if multiple recalls are issued on a given year, and after having to aggregate across many models or year models due to the fact that many vehicles share components that are recalled, we have a sample of a bit more than 100 observations. Even with this relatively small number of observations our results are very clear. The higher the correction rates of a recall, the lower the number of accidents of that year model in the three years following the recall. Other variables that are significant are the average total sales of that vehicle model in the three years of analysis, and the size of the recall, both correlated with a higher number of accidents. Regarding the indicators of the different manufacturers, Chrysler cars subject to recalls are predicted to have less accidents. The fit of this simple model is very good, with an $R^{2}$ above $80 \%$.

The results of these two sections indicate how important recalls are in reducing accidents, and how important correction rates are. Our quantitative evidence provides strikingly different evidence from the conjectures of some industry insiders, and opens the door for a policy discussion regarding the role of recalls and recall correction rates in making our roads safer.

\section{Conclusions}

In this paper we have investigated the effects of vehicle recalls on safety, measured by the number of accidents. A synthetic panel data model approach was adopted and estimated, linking government data on accidents with industry data on recalls, sales, and other market indicators. Our results show that recalls reduce accidental harm measured by the number of accidents. Recalls of a particular model reduce accidents of that model by around $20 \%$. We find that hazard recalls are more effective and so are recalls of foreign vehicles. We also find that higher correction rates of recall defects are predicted to decrease the number of accidents.

This is the first study to quantify the effects of recalls on accidental harm, supporting the intuition that recalls, if meaningful, should have some effect on safety, but against the conjectures of some industry insiders who believe that recalls are an example of over-regulation by the government.

We hope this research encourages further research regarding the benefit-cost analysis of recalls. Given the positive amount of recall costs (regardless of how large they are), the benefits of regulation should at least be positive. However, this entails a strategy to value life and the reduction of accidental harm, which is a challenging and controversial endeavor.

We also believe, that our results provide support for a more important role by insurance companies 
and the government in fostering drivers education regarding recalls. ${ }^{13}$ The lack of quantitative evidence linking recalls with increases in safety has limited the amount of support for any measure that would make possible an industry wide role in using recall information. We find that recalls reduce accidents, and that correction rates do matter. Therefore, insurance companies should consider taking into account the correction history of particular drivers and cars when pricing their insurance, and maybe even make coverage conditional on fixing major recalls. If discounts are given to drivers that have fixed their cars, we are likely to see a decline in accidents and insurance costs, with the resulting welfare improving effects for society, derived from the reduction in the monetary costs and the costs of loss of life due to accidental harm. Also, whether drivers have fixed their cars can be a good indicator of overall maintenance effort in their vehicles, likely to be correlated with the likelihood of being in an accident.

Finally, by showing empirically and quantitatively that recalls are effective, we also hope to make policy makers and the public at large aware of the fact that maybe some of those recalls, and therefore many accidents, could have been avoided. With the millions of cars recalled every year, we cannot help think that there is something rather worrisome going on, for the average American driver. We believe that manufacturers currently feel little pressure to minimize the problems of cars before they are put on the road, since the direct and indirect costs of the increasing number of recalls seem to be small compared with the likely investments (and loss of revenue due to delays in introducing new models in an ever more competitive industry) needed to reduce defects to a level that would assure a small number of recalls and prevent accidents.

\footnotetext{
13 As the investigation regarding the major recall of Ford Explorers linked to tire problems showed, the government was not collecting the appropriate information from manufacturers, and therefore the use of information by insurance companies was essentially impossible.
} 


\section{References}

[1] Attanasio, Orazio P., Weber, Guglielmo: "Consumption growth, the interest rate and aggregation," Review of Economic Studies, vol. 60, 631-649, (1993).

[2] Ashenfelter, Orley., Greenstone, Michael: "Using Mandated Speed Limits to Measure the Value of a Statistical Life,” NBER Working Paper No. 9094, (2002).

[3] Bae, Yong-Kyun: "The Effects of Vehicle Recalls on Safety: Severity Model,” Working Paper. SUNY-Stony Brook, (2004).

[4] Berry, Steven., Levinsohn, James., and Pakes, Ariel: “Automobile Prices in Market Equilibrium,” Econometrica, vol 63, 841-890, (1995).

[5] Blundell, Richard., Browning, Martin., and Meghir, Costas: "Consumer demand and the life-cycle allocation of household expenditures," Review of Economic Studies, vol. 61, 57-80, (1994).

[6] Browning, Martin., Deaton, Angus., Irish, Margaret: "A profitable approach to labour supply and commodity demand over the life-cycle," Econometrica, vol. 53, 503-543, (1985).

[7] Collado, Dolores M. : "Estimating Dynamic Models from Time Series of Independent Cross-sections," Journal of Econometrics, vol 82, 37-62, (1997).

[8] Crafton, Steven M., Hoffer, George E., and Reilly, Robert J.: "Testing the Impact of Recalls on the Demand for Automobiles," Economic Inquiry, vol. 19 (4), 694-703, (1981).

[9] Crandall, Robert W., and Graham, John D.: "Automobile Safety Regulation and Offsetting Behavior: Some Empirical Estimates," American Economic Review, vol. 74 (2), 328-331, (1984).

[10] Deaton, Angus: "Panel Data from Time Series of Cross-Sections," Journal of Econometrics, vol. 30, 109-126, (1985).

[11] Evans, Leonard: “Traffic Crashes”, American Scientist, vol. 90, 244-253, (2002).

[12] Girma, Sourafel: "A quasi-differencing approach to dynamic modelling from a time series of independent cross-sections," Journal of Econometrics, vol. 98, 365-383, (2000).

[13] Hartman, Raymond S.: "Product Quality and Market Efficiency: The Effect of Product Recalls on Resale Prices and Firm Valuation," Review of Economics and Statistics, vol. 69 (2), 367-372, (1987).

[14] Hoffer, George E., Pruitt, Stephen W., and Reilly, Robert J.: "When Recalls Matter: Factors Affecting Owner Response to Automotive Recalls," Journal of Consumer Affairs, vol. 28 (1), 96-106, (1994).

[15] Huble, Norma F., Arndt, Mark W.: "A Review of Crash Data Analysis in a Defect and Recall Investigation of the General Motors C/K Pickup Trucks," Accident Analysis and Prevention, vol. 28 (1), 33-42, (1996).

[16] Jarrell, Gregg., and Peltzman, Sam: "The Impact of Product Recalls on the Wealth of Sellers," Journal of Political Economy, vol. 93 (3), 512-536, (1985). 
[17] McKenzie, David J.: “Asymptotic theory for heterogeneous dynamic pseudo-panels," Journal of Econometrics, vol. 120, 235-262, (2004).

[18] Moffitt, Robert: "Identification and estimation of dynamic models with a time series of repeated crosssections," Journal of Econometrics, vol. 59, 99-123, (1993).

[19] NHTSA: The Impact of Motor Vehicle Crashes 2000, U.S. Department of Transportation, DOT (2002).

[20] NHTSA: National Automotive Sampling System(NASS), General Estimates System(GES), U.S. Department of Transportation, 1988-2001.

[21] NHTSA: Safety Recall Compendium, Defects and Recall Information Analysis Division, U.S. Department of Transportation, (2001).

[22] Nichols, Mark W., and Foumier, Gary M: "Recovering from a Bad Reputation: Changing Beliefs About the Quality of U.S. Autos,” International Journal of Industrial Organization, vol. 17, 299-318, (1999).

[23] Packman, John M: "Civil and Criminal Associated With Food Recalls", Food and Drug Law Journal, vol. 53, 437-452, (1998).

[24] Peltzman, Sam: “The Effects of Automobile Safety Regulation,” Journal of Political Economy, vol. 83 (4), 677-725, (1975).

[25] Power, Stephen., and Lundegaard, Karen: "Data show sharp increase in vehicle recalls," Wall Street Journal, Mar. 05, 2004.

[26] Ross, Marc., and Wenzel, Tom: "An Analysis of Traffic Deaths By Vehicle Type and Model," American Council for an Energy-Efficient Economy, Report Num T021, (2002).

[27] Rupp, Nicholas G.: "The Attributes of a Costly Recall: Evidence from the Automotive Industry," Review of Industrial Organization, vol. 25 (1), 21-44, (2004).

[28] Rupp, Nicholas G., and Taylor, Curtis R: "Who Initiates a Recall and Who Cares?: Evidence from the Automobile Industry," Journal of Industrial Economics, vol. 50 (2), 123-149, (2002).

[29] Sen, Anindya: "An Empirical Test of The Offset Hypothesis," Journal of Law and Economics, vol. 44, 481$510,(2001)$.

[30] Siwolop, Sana: “Amid a Flood of Recalls, Who's Paying Attention?" The New York Times, April. 14, (2002).

[31] Verbeek, Marno, and Nijman, T.: "Can Cohort Data Be Treated as Genuine Panel Data?" Empirical Economics, vol. 17, 9-23, (1992).

[32] Verbeek, Marno, and Vella, Francis: "Estimating dynamic models from repeated cross-sections," Journal of Econometrics, forthcoming, (2004).

[33] Viscusi, W. Rip, Vernon, John M., and Harrington, Joseph E.: Economics of Regulation and Antitrust, MIT Press, 3rd Edition, (2000).

[34] Ward's Automotive Yearbook, Annual, Detroit, MI. 

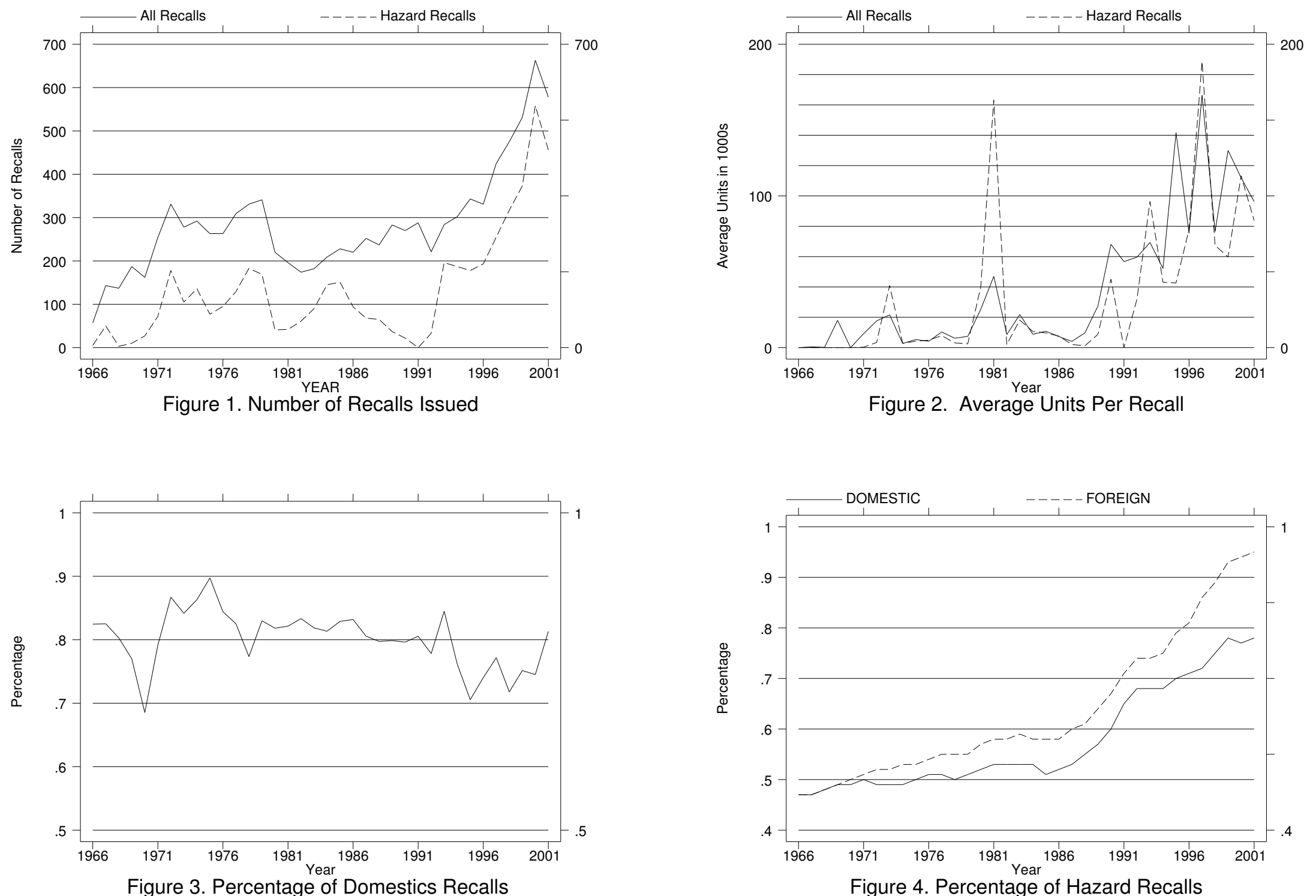

Figure 3. Percentage of Domestics Recalls 
Table 1. Summary Statistics of Recalls: 1988-2001

\begin{tabular}{|c|c|r|r||l|l|r|r|}
\hline Variable & Category & Frequency & Percent & Variable & Category & Frequency & Percent \\
\hline \hline \multirow{5}{*}{ Initiation } & MFR & 3,886 & 74.30 & Hazard & $\mathrm{A}$ & 2,870 & 54.96 \\
& ODI & 1,032 & 19.73 & & $\mathrm{~B}$ & 241 & 4.62 \\
& OVSC & 312 & 5.79 & & $\mathrm{C}$ & 2,097 & 40.16 \\
& & & & & $\mathrm{D}$ & 14 & 0.27 \\
\hline & Total & 5,230 & 100.00 & & Total & 5,222 & 100.00 \\
\hline \hline \multirow{2}{*}{ Domestic } & No & 1,208 & 23.09 & Type of & Vehicle & 4,485 & 85.71 \\
& Yes & 4,023 & 76.91 & Recall & Other $\dagger$ & 748 & 14.29 \\
\hline & Total & 5,231 & 100.00 & & Total & 5,233 & 100.00 \\
\hline
\end{tabular}

$\dagger$ Includes tires and other equipment. 
Table 2. Recalls by year: 1988-2001

\begin{tabular}{rrrrrrrr}
\hline & $(1)$ & $(2)$ & $(3)$ & $(4)$ & $(5)$ & $(6)$ & $(7)$ \\
Year & Issuance & Highest Hazard & Foreign & Voluntary & Vehicle $\dagger$ & Units per Recall & SALE $\neq$ \\
\hline \hline 1988 & 237 & 27.43 & 20.25 & 81.86 & 83.12 & 9.7 & 15.7 \\
1989 & 283 & 13.12 & 20.14 & 74.56 & 83.04 & 27.4 & 14.9 \\
1990 & 270 & 8.15 & 20.37 & 67.78 & 77.41 & 68.1 & 14.1 \\
1991 & 288 & 0.00 & 19.44 & 62.15 & 78.82 & 56.7 & 12.6 \\
1992 & 221 & 14.93 & 22.17 & 67.87 & 85.52 & 59.6 & 13.1 \\
1993 & 284 & 69.26 & 15.49 & 64.44 & 84.86 & 69.3 & 14.2 \\
1994 & 302 & 61.92 & 23.84 & 75.50 & 86.09 & 52.2 & 15.3 \\
1995 & 345 & 51.59 & 29.45 & 70.72 & 82.61 & 141.7 & 15.1 \\
1996 & 331 & 58.66 & 25.98 & 72.26 & 86.10 & 75.4 & 15.4 \\
1997 & 425 & 60.57 & 22.82 & 66.35 & 87.53 & 166.4 & 15.5 \\
1998 & 475 & 66.88 & 28.21 & 78.11 & 89.47 & 76.6 & 15.5 \\
1999 & 531 & 70.24 & 24.86 & 76.08 & 90.40 & 130.0 & 16.9 \\
2000 & 663 & 84.29 & 25.49 & 81.00 & 87.48 & 112.0 & 17.6 \\
2001 & 578 & 79.03 & 18.69 & 83.56 & 86.51 & 96.3 & 16.6 \\
\hline
\end{tabular}

\section{Source: NHTSA}

* Columns (2) to (5) are in percentages.

** Units per recall is the average number of vehicles per recall in 1,000 s.

$\dagger$ The recalls for tires and other equipment are excluded.

$\$$ Total vehicle sales in the U.S., in millions of units. 
Table 3. Characteristics of Recalls: 1988-2001

\begin{tabular}{lrrrrr}
\hline Variable & Obs & Mean & S.D. & Min & Max \\
\hline \hline Potential Number of Units Affected $\dagger$ & 5,217 & 94,237 & 625,516 & 1 & 32 \\
Potential Number of Units Defective $\dagger$ & 5,005 & 93,456 & 30,458 & 1 & 32 \\
Domestic Manufacturer & 5,231 & 0.77 & .42 & 0 & 1 \\
No. of Units Involved $\dagger$ & 4,802 & 93,994 & 652,414 & 1 & 32 \\
No. of Units Inspected with Defect $\dagger$ & 4,972 & 2,138 & 17,289 & 1 & 0.4 \\
No. of Units Corrected $\dagger$ & 4,917 & 41,814 & 192,508 & 0 & 6 \\
Ratio of Units Corrected to Units Issued & 4,802 & 0.55 & .31 & 0 & 7.5 \\
No. of Unreachable Units $\dagger$ & 4,911 & 8,477 & 400,198 & 0 & 28 \\
Hazard Category Code & 5,222 & 3.14 & .97 & 1 & 4 \\
\hline
\end{tabular}

\section{Source: NHTSA.}

$\dagger$ Units of maximum values are in millions. 
Table 4. Summary Statistics for Individual Level Observations $(n=76,239)$

\begin{tabular}{lcrrr}
\hline Variable & Mean & Std. Dev. & Min & Max \\
\hline \hline Male & .5192 & .4996 & 0 & 1 \\
Strike & .5819 & .4933 & 0 & 1 \\
Age 16 to 25 & .3174 & .4655 & 0 & 1 \\
Age 26 to 35 & .2482 & .4320 & 0 & 1 \\
Age 36 to 49 & .2413 & .4278 & 0 & 1 \\
Age 50+ & .1931 & .3947 & 0 & 1 \\
& & & & \\
Mustang & .0534 & .2249 & 0 & 1 \\
Escort & .0971 & .2961 & 0 & 1 \\
Accord & .1007 & .3009 & 0 & 1 \\
Century & .0206 & .1422 & 0 & 1 \\
Cavalier & .0889 & .2846 & 0 & 1 \\
Crown Victoria & .0284 & .1660 & 0 & 1 \\
Marquis & .0171 & .1298 & 0 & 1 \\
Cougar & .0160 & .1255 & 0 & 1 \\
Civic & .0789 & .2695 & 0 & 1 \\
Corolla & .0592 & .2359 & 0 & 1 \\
Cherokee & .0557 & .2294 & 0 & 1 \\
Sentra & .0545 & .2270 & 0 & 1 \\
Taurus & .0816 & .2737 & 0 & 1 \\
Sable & .0206 & .1420 & 0 & 1 \\
GrandAM & .0583 & .2342 & 0 & 1 \\
Camry & .0705 & .2560 & 0 & 1 \\
Altima & .0256 & .1579 & 0 & 1 \\
Intrepid & .0141 & .1179 & 0 & 1 \\
CeSabre & .0233 & .1510 & 0 & 1 \\
Aaran & .035 & 0 & 1 \\
\hline
\end{tabular}


Table 5. Summary Statistics for All accidents of Composite Types: 1988-2001. $(c=4,176)$

\begin{tabular}{|c|c|c|c|c|}
\hline Variable & Mean & Std. Dev. & Min & $\operatorname{Max}$ \\
\hline \multicolumn{5}{|c|}{ Dependent variable: } \\
\hline Ln_Acc_Type & 2.4912 & 1.0329 & -.6931 & 4.9488 \\
\hline Acc_Type & 18.2565 & 15.4668 & .5 & 141 \\
\hline \multicolumn{5}{|c|}{ Independent variables: } \\
\hline Male & .5 & .5000 & 0 & 1 \\
\hline Strike & .5 & .5000 & 0 & 1 \\
\hline Age 16 to 25 & .25 & .4331 & 0 & 1 \\
\hline Age 26 to 35 & .25 & .4331 & 0 & 1 \\
\hline Age 36 to 49 & .25 & .4331 & 0 & 1 \\
\hline Age $50+$ & .25 & .4331 & 0 & 1 \\
\hline Rec_Rate & .1428 & .2553 & 0 & 1.616 \\
\hline Rec_Rate_H & .0794 & .1921 & 0 & 1.616 \\
\hline Sales & 7.9156 & 3.7768 & 1.2669 & 16.6016 \\
\hline New Model & .4023 & .4904 & 0 & 1 \\
\hline Vintage & .4097 & .0789 & .1925 & .9866 \\
\hline Mustang & .0536 & .2253 & 0 & 1 \\
\hline Escort & .0536 & .2253 & 0 & 1 \\
\hline Accord & .0536 & .2253 & 0 & 1 \\
\hline Century & .0536 & .2253 & 0 & 1 \\
\hline Cavalier & .0536 & .2253 & 0 & 1 \\
\hline Crown Victoria & .0536 & .2253 & 0 & 1 \\
\hline Marquis & .0536 & .2253 & 0 & 1 \\
\hline Cougar & .0536 & .2253 & 0 & 1 \\
\hline Civic & .0536 & .2253 & 0 & 1 \\
\hline Corolla & .0536 & .2253 & 0 & 1 \\
\hline Cherokee & .0536 & .2253 & 0 & 1 \\
\hline Sentra & .0536 & .2253 & 0 & 1 \\
\hline Taurus & .0536 & .2253 & 0 & 1 \\
\hline Sable & .0536 & .2253 & 0 & 1 \\
\hline GrandAM & .0536 & .2253 & 0 & 1 \\
\hline Camry & .0536 & .2253 & 0 & 1 \\
\hline Intrepid & .0192 & .1371 & 0 & 1 \\
\hline Altima & .0307 & .1724 & 0 & 1 \\
\hline LeSabre & .0536 & .2253 & 0 & 1 \\
\hline Caravan & .0383 & .1920 & 0 & 1 \\
\hline
\end{tabular}


Table 6. Summary Statistics for Correction Rate Estimation

\begin{tabular}{|c|c|c|c|c|c|}
\hline Variable & Obs & Mean & Std. Dev. & Min & Max \\
\hline \multicolumn{6}{|c|}{ Dependent variable: } \\
\hline Ln_Ave_Acct & 102 & 5.04 & .7551 & 3.34 & 6.80 \\
\hline Ave_Accidents & 102 & 206.45 & 174.65 & 28.25 & 901.75 \\
\hline \multicolumn{6}{|c|}{ Independent variables: } \\
\hline Corrate & 102 & 68.85 & 21.0485 & 8.37 & 100 \\
\hline Ave_Sales & 102 & 673.53 & 556.1157 & 97.09 & 2850.51 \\
\hline Size_Recall & 102 & 2.18 & 3.4514 & .0024 & 22.16 \\
\hline Size_Square & 102 & 1.66 & 5.6735 & 0 & 49.12 \\
\hline Recalls_After & 102 & 2.10 & 2.1503 & 0 & 10 \\
\hline Hazard & 102 & .55 & .5000 & 0 & 1 \\
\hline Ford & 102 & .3627 & .4832 & 0 & 1 \\
\hline GM & 102 & .2353 & .4263 & 0 & 1 \\
\hline Chrysler & 102 & .2059 & .4063 & 0 & 1 \\
\hline Toyota & 102 & .0882 & .2850 & 0 & 1 \\
\hline Honda & 102 & .0784 & .2702 & 0 & 1 \\
\hline Nissan & 102 & .0294 & .1698 & 0 & 1 \\
\hline Year_1988 & 102 & .0686 & .254 & 0 & 1 \\
\hline Year_1989 & 102 & .0196 & .1393 & 0 & 1 \\
\hline Year_1990 & 102 & .0294 & .1698 & 0 & 1 \\
\hline Year_1991 & 102 & .0784 & .2702 & 0 & 1 \\
\hline Year_1992 & 102 & .0784 & .2702 & 0 & 1 \\
\hline Year_1993 & 102 & .0784 & .2702 & 0 & 1 \\
\hline Year_1994 & 102 & .0686 & .2541 & 0 & 1 \\
\hline Year_1995 & 102 & .1176 & .3238 & 0 & 1 \\
\hline Year_1996 & 102 & .1765 & .3831 & 0 & 1 \\
\hline Year_1997 & 102 & .1569 & .3655 & 0 & 1 \\
\hline Year_1998 & 102 & .1275 & .3351 & 0 & 1 \\
\hline
\end{tabular}

* If many recalls have been issued in a particular year,

only the most hazardous or the largest recall, if two or more have the same hazard level, is included. ** The recalls between 1999 and 2001 are not included in this sample because the accident data sets after 2001 are not available. Some recalls with very low correction rates (less than 1\%) are dropped. 
Table 7. Synthetic Panel Data Model - Grouping by the 20 Vehicle Models

\begin{tabular}{|c|c|c|c|c|}
\hline & \multicolumn{2}{|c|}{ Without Average } & \multicolumn{2}{|c|}{ With Average } \\
\hline & All Recalls & Hazard & All Recalls & Hazard \\
\hline \multicolumn{5}{|l|}{ Variables } \\
\hline \multirow[t]{2}{*}{ Recall Rate } & -.1920 & -.2731 & -.1906 & -.2654 \\
\hline & $(-2.18)$ & $(-2.25)$ & $(-2.20)$ & $(-2.22)$ \\
\hline \multirow[t]{2}{*}{ Strike } & - & - & -.6474 & -.6110 \\
\hline & - & - & $(-1.41)$ & $(-1.32)$ \\
\hline \multirow[t]{2}{*}{ Male } & - & - & -.5417 & -.5604 \\
\hline & - & - & $(-1.41)$ & $(-1.47)$ \\
\hline \multirow[t]{2}{*}{ Age 16 to 25} & - & - & 2.1424 & 2.1015 \\
\hline & - & - & $(6.25)$ & $(6.17)$ \\
\hline \multirow[t]{2}{*}{ Age 26 to 35} & - & - & 1.2776 & 1.2881 \\
\hline & - & - & (2.59) & $(2.62)$ \\
\hline \multirow[t]{2}{*}{ Age 36 to 49} & - & - & .5342 & .4506 \\
\hline & - & - & $(1.03)$ & $(0.87)$ \\
\hline \multirow[t]{2}{*}{ New Model } & .1216 & .1165 & .1014 & .0954 \\
\hline & $(2.76)$ & $(2.64)$ & $(2.33)$ & $(2.19)$ \\
\hline \multirow[t]{2}{*}{ Vintage } & .6739 & .7408 & .4906 & .5449 \\
\hline & (1.94) & $(2.10)$ & $(1.48)$ & $(1.62)$ \\
\hline \multirow[t]{2}{*}{ Sales } & .1441 & .1448 & .1288 & .1287 \\
\hline & (13.57) & $(13.71)$ & (14.67) & (14.69) \\
\hline \multirow[t]{2}{*}{ Constant } & 4.2803 & 4.2518 & 4.091 & 4.0931 \\
\hline & (20.30) & $(20.21)$ & $(9.38)$ & $(9.41)$ \\
\hline Num. of Obs & 261 & 261 & 261 & 261 \\
\hline$R^{2}$ & 0.6701 & 0.6706 & 0.8002 & 0.8008 \\
\hline
\end{tabular}

* z-statistics are in parentheses.

** Estimation also include a battery of year dummies (not shown). 
Table 8. Number of Accidents in Each Group in Each Year

\begin{tabular}{ccccccccccccccc}
\hline \hline Group no. & 1988 & 1989 & 1990 & 1991 & 1992 & 1993 & 1994 & 1995 & 1996 & 1997 & 1998 & 1999 & 2000 & 2001 \\
\hline \hline 1 & 293 & 320 & 274 & 214 & 215 & 221 & 200 & 246 & 260 & 310 & 320 & 384 & 429 & 387 \\
2 & 618 & 589 & 510 & 390 & 438 & 479 & 492 & 474 & 501 & 502 & 458 & 703 & 634 & 613 \\
3 & 335 & 345 & 446 & 459 & 535 & 615 & 561 & 523 & 530 & 573 & 542 & 669 & 760 & 781 \\
4 & 190 & 163 & 118 & 88.5 & 84 & 77 & 73 & 96 & 93 & 74 & 82 & 111 & 148 & 175 \\
5 & 491 & 450 & 413 & 416 & 426 & 467 & 428 & 429 & 348 & 444 & 421 & 692 & 720 & 633 \\
6 & 46 & 40 & 48 & 67 & 90 & 123 & 114 & 152 & 180 & 147 & 201 & 307 & 286 & 361 \\
7 & 145 & 81 & 77 & 66 & 68 & 65 & 71 & 87 & 86 & 86 & 70 & 123 & 147 & 132 \\
8 & 183 & 129 & 147 & 80 & 91 & 113 & 90 & 97 & 70 & 92 & 52 & 30 & 25 & 19 \\
9 & 264 & 273 & 295 & 285 & 313 & 399 & 382 & 421 & 374 & 467 & 466 & 628 & 708 & 738 \\
10 & 218 & 167 & 216 & 212 & 250 & 295 & 261 & 291 & 327 & 371 & 314 & 599 & 488 & 501 \\
11 & 35 & 36 & 24 & 14 & 141 & 213 & 299 & 394 & 321 & 367 & 389 & 621 & 749 & 644 \\
12 & 295 & 301 & 347 & 344 & 272 & 333 & 331 & 302 & 314 & 329 & 215 & 290 & 248 & 233 \\
13 & 193 & 255 & 325 & 262 & 316 & 507 & 476 & 443 & 412 & 488 & 484 & 657 & 705 & 695 \\
14 & 51 & 76 & 93 & 76 & 94 & 113 & 92 & 117 & 101 & 108 & 125 & 184 & 175 & 163 \\
15 & 165 & 216 & 264 & 240 & 220 & 352 & 355 & 303 & 362 & 342 & 264 & 494 & 469 & 396 \\
16 & 154 & 152 & 206 & 216 & 254 & 375 & 394 & 410 & 394 & 376 & 440 & 637 & 723 & 645 \\
17 & - & - & - & - & - & - & 71 & 151 & 182 & 252 & 212 & 327 & 379 & 377 \\
18 & - & - & - & - & - & - & - & - & - & 168 & 185 & 237 & 235 & 250 \\
19 & 121 & 107 & 109 & 106 & 120 & 129 & 142 & 104 & 118 & 116 & 108 & 141 & 175 & 181 \\
20 & - & - & - & - & 144 & 195 & 232 & 190 & 250 & 235 & 236 & 409 & 422 & 401 \\
Totals & 3,798 & 3,700 & 3,913 & 3,537 & 4,072 & 5,071 & 5,064 & 5,230 & 5,224 & 5,848 & 5,584 & 8,243 & 8,625 & 8,326 \\
\hline & & & & & & & & & & & & &
\end{tabular}

* Total number of level observation is 76,239, which is equal to the one from Table 4 . 
Table 9. Estimation of the Effect of Recalls on Accidents: Full Sample

\begin{tabular}{|c|c|c|c|}
\hline Variables & All Recalls & Domestic Recalls & Foreign Recalls \\
\hline \multirow[t]{2}{*}{$\overline{\text { Rec_Rate }}$} & -.1758 & -.1651 & -.2114 \\
\hline & $(-4.97)$ & $(-3.42)$ & $(-4.66)$ \\
\hline \multirow[t]{2}{*}{ Male } & .1574 & .2384 & -.0310 \\
\hline & (3.33) & (3.98) & $(-0.71)$ \\
\hline \multirow[t]{2}{*}{ Strike } & .2953 & .2878 & .3136 \\
\hline & (6.25) & $(4.80)$ & (7.17) \\
\hline \multirow[t]{2}{*}{ Age 16 to 25} & .2077 & -.0319 & .7648 \\
\hline & (3.11) & $(-0.38)$ & (12.36) \\
\hline \multirow[t]{2}{*}{ Age 26 to 35} & .1443 & -.0517 & .5995 \\
\hline & (2.16) & $(-0.61)$ & $(9.69)$ \\
\hline \multirow[t]{2}{*}{ Age 36 to 49} & .2001 & .0890 & .4573 \\
\hline & (3.00) & $(1.05)$ & (7.39) \\
\hline \multirow[t]{2}{*}{ New Model } & .1151 & .0410 & .0495 \\
\hline & (6.49) & (1.74) & $(2.01)$ \\
\hline \multirow[t]{2}{*}{ Vintage } & .4951 & 1.4678 & -.5804 \\
\hline & (3.44) & (7.08) & $(-3.28)$ \\
\hline \multirow[t]{2}{*}{ Sales } & .1414 & .1921 & .0776 \\
\hline & (29.69) & $(28.01)$ & (12.63) \\
\hline \multirow[t]{2}{*}{ Mustang } & .7472 & 1.0115 & \\
\hline & $(4.90)$ & (6.18) & \\
\hline \multirow[t]{2}{*}{ Escort } & .5647 & .5064 & \\
\hline & (3.74) & (3.15) & \\
\hline \multirow[t]{2}{*}{ Accord } & .6322 & & .4177 \\
\hline & (4.19) & & $(4.48)$ \\
\hline \multirow[t]{2}{*}{ Century } & -.0859 & .2009 & \\
\hline & $(-0.56)$ & $(1.22)$ & \\
\hline \multirow[t]{2}{*}{ Cavalier } & .6107 & .6100 & \\
\hline & (4.06) & (3.82) & \\
\hline \multirow[t]{2}{*}{ Crown Victoria } & .1249 & .4552 & \\
\hline & $(0.81)$ & (2.75) & \\
\hline \multirow[t]{2}{*}{ Marquis } & -.2821 & .0438 & \\
\hline & $(-1.84)$ & $(0.26)$ & \\
\hline
\end{tabular}

(continued) 
(continued)

\begin{tabular}{|c|c|c|c|}
\hline Variables & All Recalls & Domestic Recalls & Foreign Recalls \\
\hline \multirow[t]{2}{*}{ Cougar } & -.0659 & .3765 & \\
\hline & $(-0.42)$ & $(2.21)$ & \\
\hline \multirow[t]{2}{*}{ Civic } & .6985 & & .2797 \\
\hline & $(4.65)$ & & $(3.22)$ \\
\hline \multirow[t]{2}{*}{ Corolla } & .6292 & & .1283 \\
\hline & (4.17) & & $(1.53)$ \\
\hline \multirow[t]{2}{*}{ Cherokee } & -.1921 & -.2104 & \\
\hline & $(-1.28)$ & $(-1.32)$ & \\
\hline \multirow[t]{2}{*}{ Sentra } & .7712 & & .1228 \\
\hline & (5.08) & & (1.44) \\
\hline \multirow[t]{2}{*}{ Taurus } & .2607 & .0777 & \\
\hline & $(1.73)$ & $(0.48)$ & \\
\hline \multirow[t]{2}{*}{ Sable } & .1193 & .4192 & \\
\hline & $(0.78)$ & $(2.54)$ & \\
\hline \multirow[t]{2}{*}{ GrandAM } & .6138 & .7253 & \\
\hline & (4.07) & $(4.51)$ & \\
\hline \multirow[t]{2}{*}{ Camry } & .3344 & & .0735 \\
\hline & $(2.22)$ & & $(0.81)$ \\
\hline \multirow[t]{2}{*}{ Altima } & .5720 & & \\
\hline & (3.68) & & \\
\hline \multirow[t]{2}{*}{ Intrepid } & .5062 & .8105 & \\
\hline & (3.16) & $(4.70)$ & \\
\hline \multirow[t]{2}{*}{ LeSabre } & -.1129 & .1440 & \\
\hline & $(-0.74)$ & $(0.88)$ & \\
\hline \multirow[t]{2}{*}{ Constant } & .7676 & -.0363 & 2.0432 \\
\hline & $(5.00)$ & $(-0.19)$ & $(16.00)$ \\
\hline Num of Obs & 4,176 & 2,928 & 1,248 \\
\hline Num of Groups & 320 & 224 & 96 \\
\hline$R^{2}$ :within & 0.3632 & 0.3634 & 0.5360 \\
\hline$R^{2}$ :between & 0.7367 & 0.7276 & 0.8248 \\
\hline$R^{2}$ :overall & 0.5981 & 0.5828 & 0.6693 \\
\hline
\end{tabular}

* z-statistics are in parentheses.

** The vehicle model Dodge Caravan is the omitted model.

*** Estimation also include a battery of highly significant year dummies (not shown).

Breusch-Pagan Lagrange Multiplier (OLS vs. RE):

$\chi^{2}(1)=3381.64, \mathrm{P}$-value $=0.000$ for column $(1)$

$\chi^{2}(1)=2277.42, \mathrm{P}$-value $=0.000$ for column $(2)$

$\chi^{2}(1)=369.04$, P-value $=0.000$ for column $(3)$ 
Table 10. Estimation of the Effect of Recalls on Accidents: Sub-sample of Hazard Recalls

\begin{tabular}{|c|c|c|c|}
\hline Variables & All Hazard Recalls & Domestic Hazard Recalls & Foreign Hazard Recalls \\
\hline \multirow[t]{2}{*}{ Rec_Rate_H } & -.2531 & -.1932 & -.3978 \\
\hline & $(-5.18)$ & $(-2.94)$ & $(-5.66)$ \\
\hline \multirow[t]{2}{*}{ Male } & .1574 & .2384 & -.0310 \\
\hline & (3.33) & (3.98) & $(-0.71)$ \\
\hline \multirow[t]{2}{*}{ Strike } & .2953 & .2878 & .3135 \\
\hline & (6.25) & $(4.80)$ & (7.17) \\
\hline \multirow[t]{2}{*}{ Age 16 to 25} & .2077 & -.0319 & .7648 \\
\hline & (3.11) & $(-0.38)$ & (12.36) \\
\hline \multirow[t]{2}{*}{ Age 26 to 35} & .1443 & -.0517 & .5996 \\
\hline & (2.16) & $(-0.61)$ & (9.69) \\
\hline \multirow[t]{2}{*}{ Age 36 to 49} & .2001 & .0890 & .4573 \\
\hline & (3.00) & (1.05) & (7.39) \\
\hline \multirow[t]{2}{*}{ New Model } & .1107 & .0387 & .0418 \\
\hline & $(6.24)$ & (1.64) & $(1.72)$ \\
\hline \multirow[t]{2}{*}{ Vintage } & .5654 & 1.4573 & -.2703 \\
\hline & (3.85) & (7.03) & $(-1.36)$ \\
\hline \multirow[t]{2}{*}{ Sales } & .1425 & .1919 & .0772 \\
\hline & (29.90) & $(27.96)$ & (12.66) \\
\hline \multirow[t]{2}{*}{ Mustang } & .7739 & 1.0320 & \\
\hline & (5.08) & (6.31) & \\
\hline \multirow[t]{2}{*}{ Escort } & .5748 & .5222 & \\
\hline & (3.81) & (3.25) & \\
\hline \multirow[t]{2}{*}{ Accord } & .6389 & & .4151 \\
\hline & $(4.24)$ & & (4.48) \\
\hline \multirow[t]{2}{*}{ Century } & -.0881 & .1952 & \\
\hline & $(-0.58)$ & (1.19) & \\
\hline \multirow[t]{2}{*}{ Cavalier } & .6082 & .6138 & \\
\hline & $(4.05)$ & (3.84) & \\
\hline \multirow[t]{2}{*}{ Crown Victoria } & .1547 & .4738 & \\
\hline & $(1.01)$ & (2.86) & \\
\hline \multirow[t]{2}{*}{ Marquis } & -.2562 & .0618 & \\
\hline & $(-1.67)$ & $(0.37)$ & \\
\hline
\end{tabular}

(continued) 
(continued)

\begin{tabular}{|c|c|c|c|}
\hline Variables & All Hazard Recalls & Domestic Hazard Recalls & Foreign Hazard Recalls \\
\hline \multirow[t]{2}{*}{ Cougar } & -.0340 & .3934 & \\
\hline & $(-0.22)$ & $(2.31)$ & \\
\hline \multirow[t]{2}{*}{ Civic } & .6888 & & .2575 \\
\hline & $(4.58)$ & & $(3.00)$ \\
\hline \multirow[t]{2}{*}{ Corolla } & .6341 & & .1178 \\
\hline & $(4.20)$ & & $(1.41)$ \\
\hline \multirow[t]{2}{*}{ Cherokee } & -.1865 & -.1998 & \\
\hline & $(-1.24)$ & $(-1.25)$ & \\
\hline \multirow[t]{2}{*}{ Sentra } & .7774 & & .1299 \\
\hline & $(5.12)$ & & $(1.53)$ \\
\hline \multirow[t]{2}{*}{ Taurus } & .2556 & .0821 & \\
\hline & (1.69) & $(0.51)$ & \\
\hline \multirow[t]{2}{*}{ Sable } & .1254 & .4221 & \\
\hline & $(0.82)$ & $(2.56)$ & \\
\hline \multirow[t]{2}{*}{ GrandAM } & .6196 & .7359 & \\
\hline & $(4.11)$ & $(4.58)$ & \\
\hline \multirow[t]{2}{*}{ Camry } & .3292 & & .0529 \\
\hline & $(2.19)$ & & $(0.59)$ \\
\hline \multirow[t]{2}{*}{ Altima } & .5983 & & \\
\hline & $(3.85)$ & & \\
\hline \multirow[t]{2}{*}{ Intrepid } & .5125 & .8104 & \\
\hline & $(3.20)$ & $(4.70)$ & \\
\hline \multirow[t]{2}{*}{ LeSabre } & -.0929 & .1619 & \\
\hline & $(-0.61)$ & $(0.99)$ & \\
\hline \multirow[t]{2}{*}{ Constant } & .7255 & -.0418 & 1.9390 \\
\hline & $(4.72)$ & $(-0.22)$ & $(14.81)$ \\
\hline Num of Obs & 4,176 & 2,928 & 1,248 \\
\hline Num of Groups & 320 & 224 & 96 \\
\hline$R^{2}$ :within & 0.3636 & 0.3627 & 0.5400 \\
\hline$R^{2}$ :between & 0.7367 & 0.7276 & 0.8248 \\
\hline$R^{2}$ :overall & 0.5982 & 0.5825 & 0.6714 \\
\hline
\end{tabular}

* z-statistics are in parentheses.

** The vehicle model Dodge Caravan is the omitted model.

*** Estimation also include a battery of highly significant year dummies (not shown).

Breusch-Pagan Lagrange Multiplier (OLS vs. RE):

$\chi^{2}(1)=3384.40, \mathrm{P}$-value $=0.000$ for column $(1)$

$\chi^{2}(1)=2273.62, \mathrm{P}$-value $=0.000$ for column $(2)$

$\chi^{2}(1)=375.59, \mathrm{P}$-value $=0.000$ for column $(3)$ 
Table 11. Estimation of the Effect of Recalls on Accidents: Sub-sample of Striking Vehicles

\begin{tabular}{lrrr}
\hline Variables & All Recalls & Domestic Recalls & Foreign Recalls \\
\hline \hline Rec_Rate & -.1517 & -.1089 & -.2087 \\
& $(-3.10)$ & $(-1.62)$ & $(-3.44)$ \\
Male & .2035 & .2937 & -.0061 \\
& $(2.91)$ & $(3.28)$ & $(-0.10)$ \\
Age 16 to 25 & .3579 & .1233 & .9039 \\
& $(3.62)$ & $(0.97)$ & $(10.20)$ \\
Age 26 to 35 & .2040 & .0257 & .6191 \\
& $(2.06)$ & $(0.20)$ & $(6.99)$ \\
Age 36 to 49 & .2067 & .1073 & .4574 \\
& $(2.09)$ & $(0.85)$ & $(4.94)$ \\
New Model & .1544 & .0835 & .1105 \\
& $(6.29)$ & $(2.54)$ & $(3.36)$ \\
Vintage & .2947 & 1.3591 & -.9165 \\
& $(1.48)$ & $(4.70)$ & $(-3.87)$ \\
Sales & .1408 & .1866 & .0827 \\
\hline Num of Obs & 2,088 & 1,464 & 624 \\
Num of Groups & 160 & 112 & 48 \\
$R^{2}$ :within & 0.3724 & 0.3574 & 0.5891 \\
$R^{2}$ :between & 0.7411 & 0.7280 & 0.8430 \\
$R^{2}$ :overall & 0.6098 & 0.5875 & 0.7043 \\
\hline
\end{tabular}

* z-statistics are in parentheses.

** Estimation also include a battery of highly significant year dummies, and vehicle model dummies (not shown). Breusch-Pagan Lagrange Multiplier (OLS vs. RE):

$\chi^{2}(1)=1853.24$, P-value $=0.000$ for column $(1)$

$\chi^{2}(1)=1239.87$, P-value $=0.000$ for column $(2)$

$\chi^{2}(1)=212.90, \mathrm{P}$-value $=0.000$ for column $(3)$ 
Table 12. Effect of Recalls on Accidents: Sub-sample of Striking Vehicles of Hazardous Recalls

\begin{tabular}{lrrr}
\hline Variables & All Hazard Recalls & Domestic Hazard Recalls & Foreign Hazard Recalls \\
\hline \hline Rec_Rate_H & -.2174 & -.1195 & -.3614 \\
& $(-3.22)$ & $(-1.30)$ & $(-3.84)$ \\
Male & .2035 & .2937 & -.0061 \\
& $(2.91)$ & $(3.28)$ & $(-0.10)$ \\
Age 16 to 25 & .3579 & .1233 & .9039 \\
& $(3.62)$ & $(0.97)$ & $(10.20)$ \\
Age 26 to 35 & .2040 & .0257 & .6191 \\
& $(2.06)$ & $(0.20)$ & $(6.99)$ \\
Age 36 to 49 & .2067 & .1073 & .4374 \\
& $(2.09)$ & $(0.85)$ & $(4.94)$ \\
New Model & .1506 & .0821 & .1028 \\
& $(6.14)$ & $(2.49)$ & $(3.15)$ \\
Vintage & .3545 & 1.3499 & -.6646 \\
& $(1.74)$ & $(4.67)$ & $(-2.50)$ \\
Sales & .1417 & .1864 & .0828 \\
\hline Num of Obs & 2,088 & 1,464 & 624 \\
Num of Groups & 160 & 112 & 48 \\
$R^{2}$ :within & 0.3726 & 0.3569 & 0.5911 \\
$R^{2}$ :between & 0.7411 & 0.7280 & 0.8430 \\
$R^{2}$ :overall & 0.6099 & 0.5873 & 0.7053 \\
\hline
\end{tabular}

* z-statistics are in parentheses.

** Estimation also include a battery of highly significant year dummies and vehicle model dummies (not shown). Breusch-Pagan Lagrange Multiplier (OLS vs. RE):

$\chi^{2}(1)=1854.25, \mathrm{P}$-value $=0.000$ for column $(1)$

$\chi^{2}(1)=1238.65$, P-value $=0.000$ for column $(2)$

$\chi^{2}(1)=214.96$, P-value $=0.000$ for column $(3)$ 
Table 13. The Effect of Correcting Defects

\begin{tabular}{|c|c|c|c|c|}
\hline & \multicolumn{2}{|c|}{ Without Hazard } & \multicolumn{2}{|c|}{ With Hazard } \\
\hline & Coeff. & SE & Coeff. & SE \\
\hline \multicolumn{5}{|l|}{ Variables } \\
\hline Correction Rate & -.0060 & .0019 & -.0057 & .0019 \\
\hline Ave_Sales & .0010 & .0001 & .0010 & .0001 \\
\hline Size_Recall & .0865 & .0214 & .0850 & .0216 \\
\hline Size_Square & -.0513 & .0104 & -.0520 & .0105 \\
\hline Recalls_After & -.0019 & .0264 & -.0020 & .0260 \\
\hline Hazard & - & - & -.1050 & .0764 \\
\hline Ford & -.0622 & .1281 & -.0501 & .1309 \\
\hline GM & -.0996 & .1177 & -.0870 & .1182 \\
\hline Chrysler & -.2636 & .1095 & -.2562 & .1110 \\
\hline Year_1988 & -.4944 & .1557 & -.5382 & .1592 \\
\hline Year_1989 & -.5881 & .2649 & -.5980 & .2454 \\
\hline Year_1990 & -.2650 & .1922 & -.3065 & .1642 \\
\hline Year_1991 & -.2465 & .1167 & -.3201 & .1251 \\
\hline Year_1992 & -.1606 & .1333 & -.1820 & .1443 \\
\hline Year_1993 & -.2146 & .1676 & -.1949 & .1627 \\
\hline Year_1994 & -.2646 & .2506 & -.2681 & .2435 \\
\hline Year_1995 & -.5814 & .1378 & -.5928 & .1424 \\
\hline Year_1996 & -.3708 & .0993 & -.3712 & .0993 \\
\hline Constant & 5.000 & .1488 & 5.044 & .1613 \\
\hline$R^{2}$ & 0.8117 & & 0.8154 & \\
\hline
\end{tabular}


Table A1. Recall Issuance Example: Ford Mustang

\begin{tabular}{|r|l|l|r|r|}
\hline Year & Recall ID & Model-year & Units & Issue Date \\
\hline 2001 & $01 \mathrm{I} 011000$ & 2001 & 695,260 & Dec.3 \\
2001 & $01 \mathrm{~V} 390000$ & 2001 & 695,260 & Dec.3 \\
2001 & $01 \mathrm{~V} 318000$ & $1997-1994$ & & \\
2000 & $00 \mathrm{~V} 349000$ & $2000-1994$ & 434,000 & Oct.26 \\
1999 & $99 \mathrm{~V} 250000$ & $2000-1999$ & 25,306 & Sep.15 \\
1999 & $99 \mathrm{~V} 062001$ & $1999-1998$ & 898,739 & Mar.30 \\
1997 & $97 \mathrm{~V} 165000$ & 1997 & 2,250 & Sep.23 \\
1997 & $97 \mathrm{~V} 216000$ & 1997 & 8,000 & Nov.18 \\
1997 & $97 \mathrm{~V} 180000$ & $1996-1994$ & 769,000 & Oct.17 \\
1996 & $96 \mathrm{~V} 017000$ & $1993-1988$ & $7,900,000$ & Apr.15 \\
1995 & $95 \mathrm{E} 006002$ & $1995-1988$ & 8,600 & Feb.17 \\
1995 & $95 \mathrm{~V} 134000$ & 1995 & 1,300 & Jul.14 \\
1995 & $95 \mathrm{~V} 062000$ & 1994 & 54,000 & Mar.21 \\
1993 & $93 \mathrm{~V} 159000$ & 1993 & 4,100 & Sep.21 \\
1992 & $92 \mathrm{~V} 063000$ & $1985-1984$ & 306,000 & Apr.24 \\
1991 & $91 \mathrm{~V} 048000$ & 1991 & 6,800 & Mar.12 \\
1987 & $87 \mathrm{~V} 139000$ & $1987-1986$ & $3,600,000$ & Sep.1 \\
1985 & $85 \mathrm{~V} 068000$ & 1985 & 14,000 & May.14 \\
\hline
\end{tabular}


Table A2. Variable Definition

\begin{tabular}{|c|c|}
\hline Variable & Description \\
\hline \multicolumn{2}{|l|}{ Dependent variable: } \\
\hline Acc_Type & Number of accidents of a composite type \\
\hline Ln_Acc_Type & The natural logarithm of Acc_Type \\
\hline \multicolumn{2}{|c|}{ Driver characteristics } \\
\hline Male & 1 if driver is male \\
\hline Strike & 1 if the vehicle struck other vehicles or objects \\
\hline Age 16 to 25 & 1 if driver's age is less than 26 \\
\hline Age 26 to 35 & 1 if driver's age is between 26 and 35 \\
\hline Age 26 to 49 & 1 if driver's age is between 36 and 49 \\
\hline Age $50+$ & 1 if driver's age is 50 or higher \\
\hline \multicolumn{2}{|c|}{ Vehicle characteristics } \\
\hline New Model & 1 if there is any substantial design change within the last 5 years \\
\hline Vintage & The ratio of current and last year's vehicle stocks to total 5 year stock \\
\hline Sales & The number of vehicles sold in the previous 4 years in $100,000 \mathrm{~s}$ of units \\
\hline Mustang & 1 if the vehicle model is Ford Mustang \\
\hline$\ldots \ldots \ldots \ldots \ldots+\ldots$ & Other vehicle models \\
\hline \multicolumn{2}{|c|}{ Recall characteristics } \\
\hline Rec_Rate & $\begin{array}{l}\text { The ratio of units recalled to units sold } \\
\text { in the previous } 4 \text { years }\end{array}$ \\
\hline Rec_Rate_H & $\begin{array}{l}\text { The ratio of high hazard units recalled to units sold } \\
\text { in the previous } 4 \text { years }\end{array}$ \\
\hline \multicolumn{2}{|c|}{ Other characteristics } \\
\hline Year_1988 to 2001 & Year Dummies for the 1988 to 2001 period \\
\hline
\end{tabular}

$\dagger$ Other vehicle dummies. 20 vehicle models are included. 
Table A3. Variable Definition for Correction Rate Estimation

\begin{tabular}{ll}
\hline Variable & Description \\
\hline \hline Dependent variable: & \\
Ln_Ave_Acct $\dagger$ & The natural logarithm of the average number of accidents within 3 years \\
Independent variables: & \\
Correction Rate & Correction rates of a recall $i, 18$ months after issuance \\
Ave_Sales $\dagger$ & Vehicles' Sales (Units: 1,000 vehicles) \\
Size_Recall & The size of a recall (in vehicle Units: 100,000) \\
Size_Square & The square of the size of the recall \\
Recalls_After & The number of recalls after the recall $i$ within 3 years \\
Hazard & Whether the recall was category A or B (Hazardous) \\
Ford & Manufacturer dummy \\
$\cdots . . \neq$ & Other manufacturer dummies \\
Year_1988 to 2001 & Year dummies for the 1988 to 2001 period \\
\hline
\end{tabular}

$\dagger$ When a recall covers many vehicle models we sum them up.

$\ddagger$ Other manufacturers dummies.

Table A4. Vehicle Models

\begin{tabular}{|l|l||l|l|}
\hline Variable & Vehicle Models & Variable & Vehicle Models \\
\hline Mustang & Ford Mustang & Accord & Honda Accord \\
Century & Ford Escort & Civic & Honda Civic \\
Cavalier & Chevrolet Cavalier & Sentra & Nissan Sentra \\
Crown Victoria & Ford Crown Victoria & Camry & Toyota Camry \\
Marquis & Mercury Marquis & Intrepid & Dodge Intrepid \\
Cougar & Mercury Cougar & LeSabre & Buick LeSabre \\
Cherokee & Jeep Cherokee & Caravan & Dodge Caravan \\
Taurus & Ford Taurus & Altima & Nissan Altima \\
Sable & Mercury Sable & & \\
GrandAM & Pontiac Grand AM & & \\
\hline
\end{tabular}

